\title{
Vasoinhibins regulate the inner and outer blood-retinal barrier and limit retinal oxidative stress
}

\author{
David Arredondo Zamarripa, Nundehui Díaz-Lezama, Rodrigo Meléndez García, \\ Jesús Chávez Balderas, Norma Adán, Maria G. Ledesma-Colunga, Edith Arnold, Carmen Clapp and \\ Stéphanie Thebault*
}

Departamento de Neurobiología Celular y Molecular, Instituto de Neurobiología, Universidad Nacional Autónoma de México, Querétaro, México

\section{Edited by:}

Dirk M. Hermann, University

Hospital Essen, Germany

Reviewed by:

Stefan Liebner, Goethe University

Clinic, Germany

Nina Hagemann, University Hospital

Essen, Germany

*Correspondence:

Stéphanie Thebault, Instituto de Neurobiología, Universidad Nacional

Autónoma de México, Campus UNAM-Juriquilla, Blvd Juriquilla 3001, 76230 Querétaro, Querétaro,

México

e-mail: stephaniethebault@

gmail.com
Vasoinhibins are prolactin fragments present in the retina, where they have been shown to prevent the hypervasopermeability associated with diabetes. Enhanced bradykinin (BK) production contributes to the increased transport through the blood-retina barrier (BRB) in diabetes. Here, we studied if vasoinhibins regulate BRB permeability by targeting the vascular endothelium and retinal pigment epithelium (RPE) components of this barrier. Intravitreal injection of BK in male rats increased BRB permeability. Vasoinhibins prevented this effect, as did the B2 receptor antagonist Hoe-140. BK induced a transient decrease in mouse retinal and brain capillary endothelial monolayer resistance that was blocked by vasoinhibins. Both vasoinhibins and the nitric oxide (NO) synthase inhibitor L-NAME, but not the antioxidant N-acetyl cysteine (NAC), blocked the transient decrease in bovine umbilical vein endothelial cell (BUVEC) monolayer resistance induced by BK; this block was reversed by the NO donor DETANONOate. Vasoinhibins also prevented the BK-induced actin cytoskeleton redistribution, as did L-NAME. BK transiently decreased human RPE (ARPE-19) cell monolayer resistance, and this effect was blocked by vasoinhibins, L-NAME, and NAC. DETANONOate reverted the blocking effect of vasoinhibins. Similar to BK, the radical initiator Luperox induced a reduction in ARPE-19 cell monolayer resistance, which was prevented by vasoinhibins. These effects on RPE resistance coincided with actin cytoskeleton redistribution. Intravitreal injection of vasoinhibins reduced the levels of reactive oxygen species (ROS) in retinas of streptozotocin-induced diabetic rats, particularly in the RPE and capillary-containing layers. Thus, vasoinhibins reduce BRB permeability by targeting both its main inner and outer components through NO- and ROS-dependent pathways, offering potential treatment strategies against diabetic retinopathies.

Keywords: vasoinhibins, 16K prolactin, blood-retina barrier, retinal pigment epithelium, nitric oxide, reactive oxygen species, oxidative stress, diabetes

\section{INTRODUCTION}

The functional integrity of the blood-retinal barrier (BRB) is crucial for proper vision. The BRB consists of inner and outer components that are mainly formed by vascular endothelial and retinal pigment epithelial (RPE) cells, respectively (Klaassen et al., 2013). Diverse conditions, including aging and diabetes, are associated with excessive transport through the BRB (Gardner et al., 2002; Klaassen et al., 2013). In this respect, increased levels of bradykinin (BK), a hypotensive peptide that belongs to the kinin-kallikrein system (Leeb-Lundberg et al., 2005), have been detected in the vitreous of patients with diabetic retinopathy (Gao et al., 2007), and the intravitreal injection of both BK and the enzyme that produces $\mathrm{BK}$ from high molecular weight kininogen (prekallikrein) induce excessive permeability through the BRB causing edema in rats (Phipps et al., 2009; Clermont et al., 2011). In addition, kinin receptor antagonists prevent the increase in retinal vascular permeability due to diabetes in rats (Abdouh et al., 2008).
Kinin receptors occur in two isoforms: the $\mathrm{B} 2$ receptor, which is ubiquitously and constitutively expressed (Sainz et al., 2007), and the B1 receptor, which is minimally expressed under physiological conditions but up-regulated during tissue injury and inflammation (Marceau and Regoli, 2004; Leeb-Lundberg et al., 2005). BK binds preferentially to the $\mathrm{B} 2$ receptor (Charest-Morin et al., 2014), which has been detected in the human retina (Takeda et al., 1999). In rodents, there is functional evidence of its presence in retinal capillary endothelial (Abdouh et al., 2003) and RPE (Ma et al., 1996; Lim et al., 2008, 2009) cells. Stimulation of the $\mathrm{B} 2$ receptor has been shown to promote vascular permeability in endothelial cells of the blood-brain barrier (Revest et al., 1991; Doctrow et al., 1994; Easton and Abbott, 2002; Raslan et al., 2010) by increasing the production of both nitric oxide (NO) via $\mathrm{Ca}^{2+} / \mathrm{CaM}$ kinase II activation (Cai et al., 2008) and of reactive oxygen species (ROS) via arachidonic acid (Easton and Abbott, 2002) and NADPH oxidase activation (Fischer et al., 2005). Both NO and ROS cause cytoskeleton reorganization and 
subsequent tight and adherens junction reorganization (De Bock et al., 2013) that, together, control endothelial cell permeability. On the other hand, NO is known to contribute to the integrity of RPE tight junctions (Zech et al., 1998), and increased ROS production correlates with increased permeability through RPE (Miura and Roider, 2009; Qin and Rodrigues, 2010; Kim et al., 2012).

A major feature of aging- and diabetes-related retinopathies is the excessive production of NO and ROS (Zheng and Kern, 2009). Therefore, more insight into the action mechanisms of molecules that can modulate the BK pathway will contribute to retinal health. Vasoinhibins, a family of peptides originating from the proteolysis of the hormone prolactin (Clapp et al., 2006), have been demonstrated to antagonize several effects of $\mathrm{BK}$, including vasorelaxation, vascular production of NO (Gonzalez et al., 2004), and endothelial cell proliferation (Thebault, 2011). Moreover, vasoinhibins prevent the excessive vasopermeability associated with diabetes (Garcia et al., 2008). In this study, we investigated whether vasoinhibins reduce the BK-induced increase in BRB permeability by targeting both the endothelial and the RPE components of this barrier. We also wished to ascertain whether NO and ROS mediate these effects. To this end, we quantified transport through the BRB using the Evans blue dye method in rats, and we used monolayers of freshly isolated mouse retinal and brain capillary endothelial cells, BUVEC and ARPE-19 to assess trans-electrical resistance (TER). We also analyzed the filamentous (F-) actin distribution and contribution of the kinin $\mathrm{B} 2$ and $\mathrm{B} 1$ receptors, NO, and ROS to the mechanism of vasoinhibin action using selective pharmacological agonists and/or inhibitors. Our data support the hypothesis that vasoinhibins regulate endothelial and RPE cell permeability; furthermore, they showed that vasoinhibins attenuate diabetes-related oxidative stress in the retina, and that $\mathrm{NO}$ and ROS differentially contribute to the regulation of permeability through endothelial and RPE cell monolayers.

\section{MATERIALS AND METHODS REAGENTS}

The vasoinhibins used in in vivo experiments corresponding to the $16 \mathrm{kDa}$ fragment were generated by the enzymatic cleavage of rat prolactin from mammary gland extracts as previously described (Clapp et al., 1993). Recombinant human vasoinhibins (corresponding to a $14-\mathrm{kDa}$ fragment of prolactin) used in cell culture experiments were generated by site-directed mutagenesis as previously described (Galfione et al., 2003). Other compounds including $\mathrm{BK}, \mathrm{N} \omega$-Nitro-L-arginine methyl ester hydrochloride (L-NAME), (Z)-1-[2-(2-aminoethyl)- $N$-(2-ammonioethyl)amino] diazen-1-ium-1,2-diolate (DETANONOate), $\mathrm{N}$-acetylcysteine (NAC), Luperox (tert-butyl peroxide), the kinin B2 receptor antagonist Hoe-140, and the Evans blue dye were purchased from Sigma-Aldrich (St. Louis, MO), and the 5,59,6,69-tetrachloro-1,19,3,39 tetraethylbenzimidazolylcarbocyanine iodide JC-1 dye was from Molecular probes (Eugene, OR). The monoclonal anti-kinin B2 receptor, the polyclonal anti-kinin $\mathrm{B} 1$ receptor, and polyclonal anti- $\beta$-tubulin antibodies were purchased from BD Biosciences (610451), Santa Cruz Biotechnology (sc-15048), and ZYMED (22833), respectively.
Secondary antibodies conjugated to alkaline phosphatase (Bio-Rad Laboratories, Hercules, CA) were used.

\section{ETHICS STATEMENT}

All experiments were approved by the Bioethics Committee of the Institute of Neurobiology (INEU/SA/CB/074) from the National University of Mexico (UNAM, clave NOM-062-ZOO-1999) in accordance with the rules and regulation of the Society for Neuroscience: Policies on the Use of Animals and Humans in Neuroscience Research. All efforts were made to minimize the number of animals used and their suffering.

\section{ANIMALS}

Male albino rats (Wistar, 250-350 g) were fed ad libitum and reared in normal cyclic light conditions (12h light: $12 \mathrm{~h}$ dark). A group of rats received L-NAME $(1.8 \mathrm{mM})$ in drinking water for 15 days. Sprague-Dawley rats were immunized with Complex Freund's Adjuvant (Adan et al., 2013). For all procedures, rats were anesthetized with ketamine/xylazine (7/3). Additional anesthesia was provided throughout the procedures as needed. Diabetes was induced with a single intraperitoneal injection of streptozotocin $(60 \mathrm{mg} / \mathrm{kg}$ ) in Wistar rats (Garcia et al., 2008), and animals with glucose levels greater than $250 \mathrm{mg} / \mathrm{dl}$ were used 4 weeks after diabetes induction.

\section{CELLS}

BUVEC (Cajero-Juarez et al., 2002) were grown in F12K culture medium supplemented with $10 \%$ fetal bovine serum, $50 \mathrm{U} / \mathrm{ml}$ penicillin/streptomycin, and 1\% fungizone (Life Technologies, Grand Island, NY). The ARPE-19 human cell line (ATCC Number: CRL-2302) (Dunn et al., 1996) was grown in Dulbecco's Modified Eagle's Medium nutrient mixture F12 supplemented with $1 \%$ fetal bovine serum. Cell cultures were cultured at an initial density of $10^{6}$ cells and maintained at $37^{\circ} \mathrm{C}$ and $5 \% \mathrm{CO}_{2}$.

\section{PRIMARY CULTURES OF MOUSE BRAIN (MBCEC) AND RETINAL (MRCEC) CAPILLARY ENDOTHELIAL CELLS}

We isolated MBCEC and MRCEC from the mouse brain and retina using collagenase digestion and magnetic-activated cell sorting (MACS), ensuring a preparation of $>90 \%$ purity. Briefly, brains (devoid of cerebellum) and retinas from five to twenty Cd-1 mice (4 weeks of age) were aseptically collected and rinsed in Hank's Balanced Salt Solution (GIBCO BRL, New York, NY) supplemented with $1 \%$ bovine serum albumin (BSA) and $1 \%$ penicillin/streptomycin, and were cut into small pieces. Tissue was digested with $0.1 \%$ collagenase type 1 for $45 \mathrm{~min}$ at $37^{\circ} \mathrm{C}$ under agitation $(350 \mathrm{rpm})$. The cell-suspension was then filtered through 70-micron mesh and centrifuged at $1200 \mathrm{rpm}$ for $10 \mathrm{~min}$ at $4^{\circ} \mathrm{C}$. Supernatant from the brain-derived suspension was discarded, and the pellet was treated with $2 \mathrm{~mL}$ of erythrocyte lysis buffer for $5 \mathrm{~min}$ and centrifuged. Finally, CD31-positive cells from both brain and retinal populations were isolated by MACS as previously described (Smith et al., 2014).

\section{INTRAVITREAL INJECTIONS}

Rats were injected intravitreously as reported (Aranda et al., 2005). The final injection volume was $5 \mu$ l. One eye was injected 
with $\mathrm{BK}$ ( 60 pg per eye, corresponding to $1 \mathrm{nM}$ as the estimated volume of rat vitreous is $60 \mu \mathrm{l}$, Guo et al., 2007) and the contralateral eye with $\mathrm{BK}$ combined with vasoinhibins $(1 \mu \mathrm{g}, 1 \mu \mathrm{M})$ or with the kinin B2 receptor antagonist Hoe-140 (235 ng, $3 \mu \mathrm{M})$. The control groups consisted of rat eyes injected with vehicle (PBS), and the contralateral eye received vasoinhibins $(1 \mu \mathrm{M})$ or Hoe-140 $(3 \mu \mathrm{M})$.

\section{QUANTIFICATION OF BRB PERMEABILITY}

The Evans blue dye permeation assay was performed as previously described (Xu et al., 2001; Garcia et al., 2008). It is however worth mentioning that Evans blue dye was administered $2 \mathrm{~h}$ after intravitreous injections, and left circulation for 2 additional hours.

\section{REAL-TIME PCR}

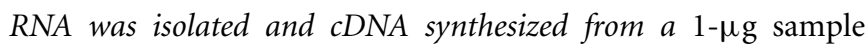
as previously described (Arnold et al., 2014). Primer sequences are documented in Table 1 , and the conditions used for the PCR reactions were as previously described (Arnold et al., 2014). Cycle thresholds normalized to the housekeeping gene hypoxanthine-guanine phosphoribosyltransferase (HPRT) were used to calculate the mRNA levels of interest.

\section{WESTERN-BLOT}

Rat retinas and knees were homogenized in 0.5\% Nonidet P-40, $0.1 \%$ SDS, $50 \mathrm{mM}$ Tris, $150 \mathrm{mM} \mathrm{NaCl}, 1 \mathrm{mM}$ phenylmethylsulnonyl fluoride, and $1 \mathrm{mM}$ aprotinin $(\mathrm{pH} 7)$ and centrifuged $(10,000 \mathrm{~g}$ for $10 \mathrm{~min})$. Supernatant proteins $(40 \mu \mathrm{g})$ were resolved by 7.5 or $10 \%$ SDS-polyacrylamide gels under reducing conditions, transferred to nitrocellulose membranes, and probed with an anti-kinin B2 or B1 receptor (1:500 and 1:50 dilution, respectively) and anti- $\beta$-tubulin (1:1000 dilution) antibodies. Primary antibodies were revealed using secondary antibodies conjugated to alkaline phosphatase. Optical density values were determined using the Quantity One, 1-D analysis software (Bio-Rad, Hercules, CA).

\section{F-ACTIN STAINING}

Cells were grown on matrigel-coated coverslips until confluence. After treatment, cells were fixed with 4\% paraformaldehyde for $10 \mathrm{~min}$ at room temperature. Then cells were washed twice with PBS and permeabilized with $0.1 \%$ Triton X-100 in PBS for $5 \mathrm{~min}$. Changes in F-actin structures were detected by incubating the cells for $20 \mathrm{~min}$ at room temperature with a 1:100 dilution of TRITC-labeled phalloidin (Molecular Probes). Coverslips were then washed twice with PBS and mounted in VECTASHIELD ${ }^{\circledR}$

\begin{tabular}{|c|c|c|c|c|}
\hline mRNA & $\begin{array}{l}\text { NCBI } \\
\text { accession } \\
\text { number }\end{array}$ & $\begin{array}{l}\text { Forward } \\
\text { sequence }\end{array}$ & $\begin{array}{l}\text { Reverse } \\
\text { sequence }\end{array}$ & $\begin{array}{c}\text { Primer } \\
\text { efficiency } \\
(\%)\end{array}$ \\
\hline Hprt & NM_012583.2 & $\begin{array}{l}\text { TTGCTGACCT } \\
\text { GCTGGATTAC }\end{array}$ & $\begin{array}{l}\text { GTTGAGAGATCA } \\
\text { TCTCCACC }\end{array}$ & 100.8 \\
\hline B2R & NM_173100.2 & $\begin{array}{l}\text { CCCTTCCTCT } \\
\text { GGGTCCTCTT }\end{array}$ & $\begin{array}{l}\text { CAGAACACGCT } \\
\text { GAGGACAAAGA }\end{array}$ & 93.5 \\
\hline
\end{tabular}

mounting medium with DAPI. Images were obtained using a LSM 510 confocal laser scanning microscope (Carl Zeiss, Jena, Germany).

\section{MEASUREMENT OF TER}

BUVEC, MRCEC, MBCEC, and ARPE-19 cells were grown on $1.12-\mathrm{cm}^{2}$ Transwell clear polyester membrane inserts (Corning Inc., Corning, NY) with pore sizes of $8.0 \mu \mathrm{m}$ for BUVEC and $0.4 \mu \mathrm{m}$ for other cells, and monitored until stabilization of TER (average of 180 to $200 \Omega . \mathrm{cm}^{2}$ ) using the EVOM2 Epithelial Voltohmmeter (World Precision Instrument). TER was then measured over a 90-min period from each insert unless another time period is specified. TER values were expressed as percent of control (complete medium) at time 0 .

\section{ASSESSMENT OF MITOCHONDRIAL ROS PRODUCTION USING JC-1 DYE}

Hyperpolarization of the mitochondrial membrane potential results in increased ROS generation (Teshima et al., 2014). The JC-1 dye is freely permeable to cells and undergoes reversible transformation from a monomer (emitting at $\sim 530 \mathrm{~nm}$ (green) in response to a 535-nm excitation) to an aggregate form (emitting red fluorescence at $\sim 590 \mathrm{~nm}$ (red) in response to a $485-\mathrm{nm}$ excitation) when it binds to hyperpolarized mitochondrial membranes (Cossarizza et al., 1993). A decrease in the aggregate fluorescence (red; 590) is indicative of depolarization, whereas an increase indicates hyperpolarization. BUVEC $\left(1 \times 10^{5}\right.$ cells/well $)$ and ARPE-19 $\left(1.5 \times 10^{5}\right.$ cells/well $)$ cells in 96-well plates were treated as indicated in Figures 4E, 6D diagrams. The cells were then washed and incubated in the dark with $10 \mu \mathrm{g} / \mathrm{mL} \mathrm{JC}-1$ dye at $37^{\circ} \mathrm{C}$ for $10 \mathrm{~min}$. The mitochondrial membrane potential was measured using a bioplate reader (Victor $^{3} \mathrm{~V}$ [Perkin Elmer]; green fluorescence, $530 \mathrm{~nm}$; red fluorescence, $570 \mathrm{~nm}$ ).

\section{MEASUREMENT OF SUPEROXIDE USING THE VICTOR ${ }^{3}$ V MICROPLATE READER}

Superoxide levels were monitored according to the Manufacturer's instructions (The Enzo Life Sciences' Total ROS/Superoxide detection kit; ENZ-51010).

\section{FLUORESCENT DETECTION OF INTRACELLULAR ROS}

The in vivo production of ROS in the retina was assessed using dihydroethidium (DHE) staining. First, eyes were fixed in $4 \%$ PFA for $4 \mathrm{~h}$ and then placed in $15 \%$ sucrose for 1 day. Eyes were frozen (Tissue-Tek; Sakura Finetek, Torrance, CA), and 20$\mu \mathrm{m}$ cryostat sections were mounted on gelatin-coated slides. In a dark chamber, retinal sections were loaded with $5 \mu \mathrm{M}$ DHE for $30 \mathrm{~min}$ at room temperature and then washed thrice in PBS. Sections were mounted on glass slides with VECTASHIELD ${ }^{\circledR}$ mounting medium with DAPI, and the slides were analyzed without delay using a LSM 510 confocal laser-scanning microscope. Images were obtained using an Apo-406 objective. The same acquisition settings were used for all experiments to allow direct comparison of retinal explants. Digital images were processed using free ImageJ software (Rasband, W.S., ImageJ; U.S. NIH, Bethesda). Only cropping of images was performed; there was no adjustment of brightness. The mean fluorescence intensity ratio of each retinal layer was determined in 6 different regions of 

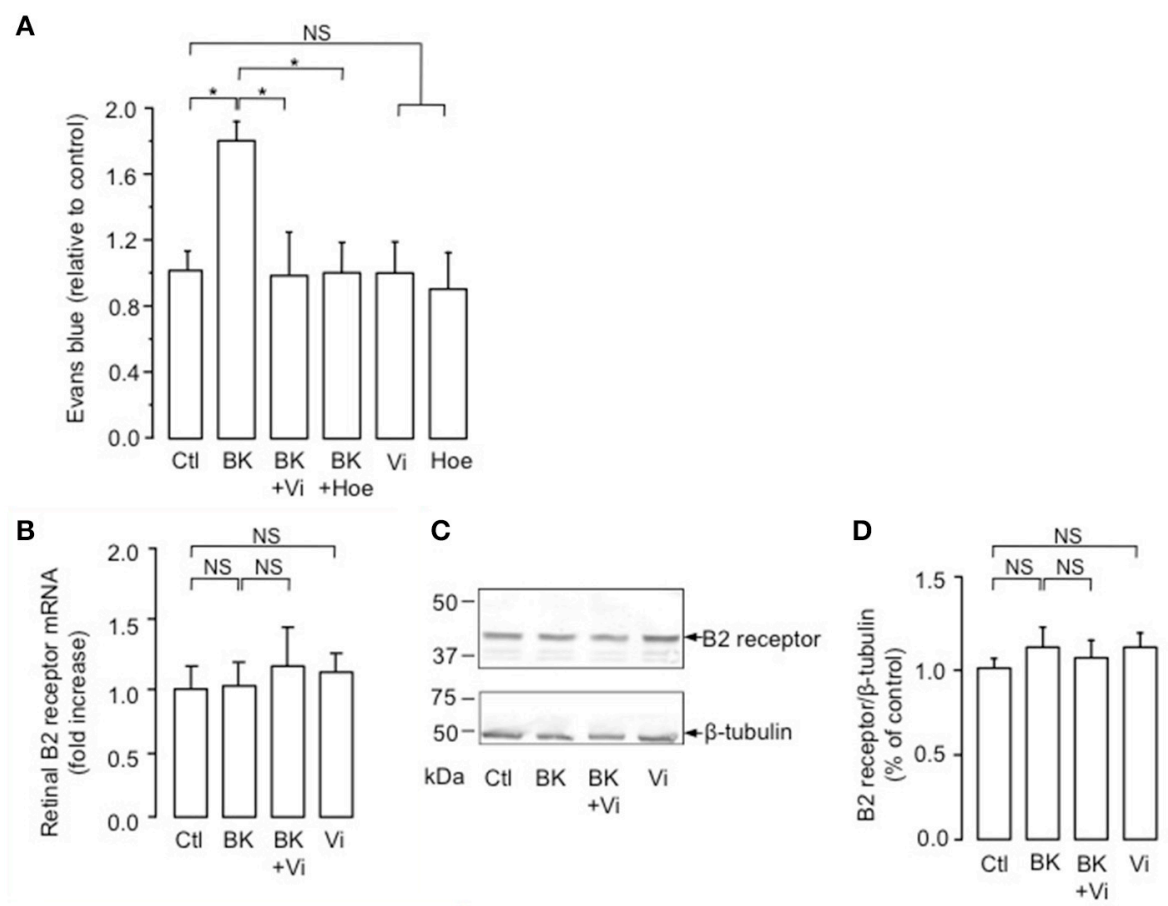

E

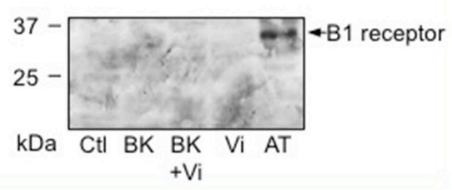

FIGURE 1 | Vasoinhibins prevent BK-induced increase in BRB permeability similarly to a kinin B2 receptor antagonist. (A) Evaluation of the Evans blue dye content in retinas of rats intravitreously injected $4 \mathrm{~h}$ earlier with PBS (Ctl), BK (1 nM), BK combined with either vasoinhibins $(\mathrm{Vi}, 1 \mu \mathrm{M})$ or Hoe-140 (Hoe, $3 \mu \mathrm{M}$ ), Vi alone, or Hoe alone. Values are mean \pm s.e.m. normalized to the control ( $n=8-16$ per group; ${ }^{*} P<0.05$ ). (B-D) Retinas of rats that were intravitreously injected $4 \mathrm{~h}$ earlier with $\mathrm{PBS}, \mathrm{BK}, \mathrm{Vi}$, or $\mathrm{BK}$ combined with Vi were analyzed for kinin $B 2$ receptor mRNA ( $B$, mean \pm s.e.m. from 5 independent experiments) and protein (C). Total $\beta$-tubulin served as loading control. (D) Quantification of kinin B2 receptor by densitometry normalized to total $\beta$-tubulin. Values correspond to the mean \pm s.e.m. from 3 independent experiments. (E) Retinas of rats that were intravitreously injected $4 \mathrm{~h}$ earlier with PBS, BK, Vi, or BK combined with $\mathrm{Vi}$ were analyzed for kinin B1 receptor protein. Total knee extract from rats with Freund's adjuvant-induced arthritis (AT, arthritic tissue) was used as a positive control for B1 receptor expression. NS, not significant. interest (same size), distributed equally over the full layer, from one retinal section per time point (each of which was representative of 3 experiments). The ratio between PBS (numerator) and vasoinhibins, time-matched control retinas was calculated by 2 single-blind, independent observers to determine superoxide anion production in specific treatment groups.

\section{STATISTICAL ANALYSIS}

All results were replicated in three or more independent experiments. Data were presented as mean \pm s.e.m.; all data showed normal distribution or equal variance according to Kolmogorov-Smirnov and Levene's tests, respectively. Statistical differences among groups were determined by OneWay ANOVA followed by Bonferroni's post-hoc comparison test (Sigma Stat 7.0, Systat Software Inc., San Jose, CA). Differences in means with $P<0.05$ were considered statistically significant.

\section{RESULTS}

\section{VASOINHIBINS PREVENT BK-INDUCED INCREASE IN BRB} PERMEABILITY SIMILARLY TO A KININ B2 RECEPTOR ANTAGONIST

The intravitreal injection of $B K$ induced a 1.8 -fold increase in the basal transport through the BRB compared to the PBS-injected eyes (Ctl) (Figure 1A). When coinjected with BK, vasoinhibins prevented the $\mathrm{BK}$-induced increase in $\mathrm{BRB}$ permeability in a manner similar to that of the competitive kinin $\mathrm{B} 2$ receptor antagonist Hoe-140 (Figure 1A). Alone, vasoinhibins or Hoe-140 did not modify the transport through the BRB. Signaling through the kinin B2 receptor has been shown to be primarily controlled by short-term mechanisms including both receptor desensitization (Mathis et al., 1996) and internalization (Munoz and LeebLundberg, 1992; Munoz et al., 1993), but it can also be regulated by changes in expression levels of the receptor (Nostramo et al., 2013). Thus, retinas of animals that were intravitreally injected with BK, vasoinhibins, or both were analyzed for B2 receptor mRNA and protein levels by real-time PCR and Western-blot, 

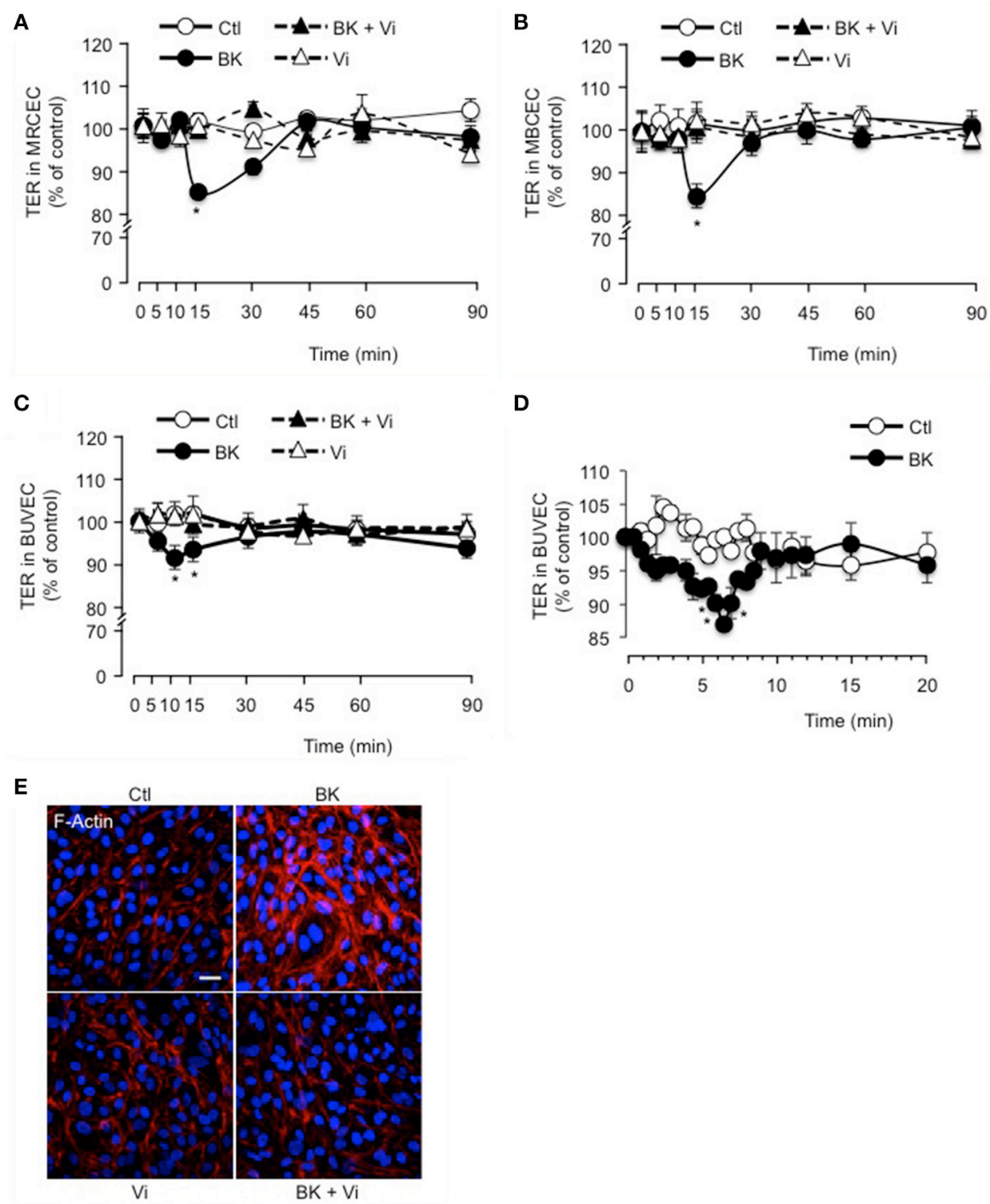

FIGURE 2 | Vasoinhibins block BK-induced reduction of transendothelial resistance and morphological changes in actin cytoskeleton. Time course of trans-electrical resistance (TER) in MRCEC (A) and MBCEC (B) monolayers cultured in complete medium (CtI) with or without $10 \mu \mathrm{M}$ BK and $10 \mathrm{nM}$ vasoinhibins (Vi). (C) TER in BUVEC monolayers cultured in complete medium (Ctl) with or without $10 \mu \mathrm{M}$ BK and $10 \mathrm{nM}$ Vi. (D) Expanded early time values of experiment (C). In (A-D),

respectively. The retinal levels of B2 receptor mRNA (Figure 1B) and protein (Figure 1C) were not different between PBS-, BK-, $\mathrm{Vi-}$, and (BK + Vi)-injected eyes. Figure 1D shows quantification of $\mathrm{B} 2$ receptor after normalization for the amount of $\beta$-tubulin on the gel. Treatment with BK has been shown to induce the kinin B1 receptor (Phagoo et al., 1999). However, in addition to being absent in rat retina under physiological conditions, the B1 receptor is also absent after BK injection, combined or not with vasoinhibins (Figure 1E). Total knee extract from rats subjected values are mean \pm s.e.m. from 3 independent experiments normalized to the control; $* P<0.05$ vs. CtI. MBCEC and MRCEC were cultured on inserts with pore sizes of $0.4 \mu \mathrm{m}$ while BUVEC cells were cultured on inserts with pore sizes of $8.0 \mu \mathrm{m}$. (E) BUVEC were cultured in complete medium (Ctl) with or without $10 \mu \mathrm{M}$ BK and $10 \mathrm{nM} \mathrm{Vi}$ for $15 \mathrm{~min}$ and then actin cytoskeleton (F-actin) distribution was determined using rhodamine-phalloidin. Representative fields are shown. Scale bar, $10 \mu \mathrm{m}$.

to the adjuvant model of inflammatory arthritis for 21 days (Adan et al., 2013) was used as a positive control for B1 receptor expression. Notably, the band detected in arthritic tissue (AT) with the polyclonal anti-B1 receptor antibody migrates at an apparent molecular weight of $35 \mathrm{kDa}$, the molecular mass of the B1 receptor (see http://datasheets.scbt.com/sc-15048.pdf), thus validating the efficacy of the Western blot detection. These data indicate that vasoinhibins mitigate the BK-mediated increase in BRB permeability, that this results from kinin $\mathrm{B} 2$, but not $\mathrm{B} 1$, receptor 
A

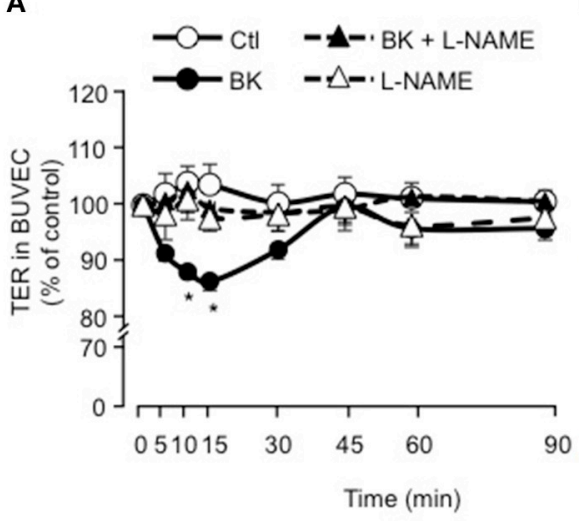

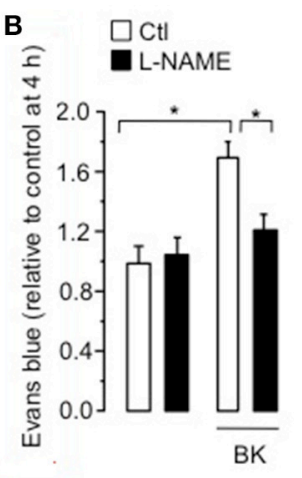

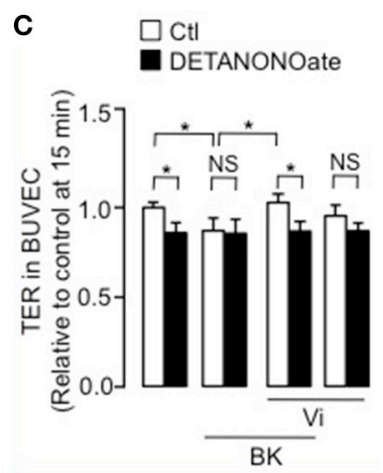

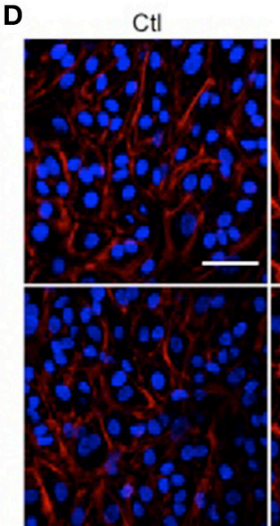

L-NAME

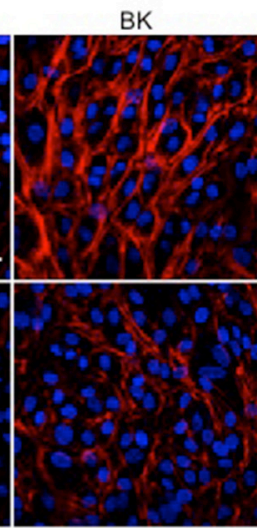

$B K+$ L-NAME
DETANONOate

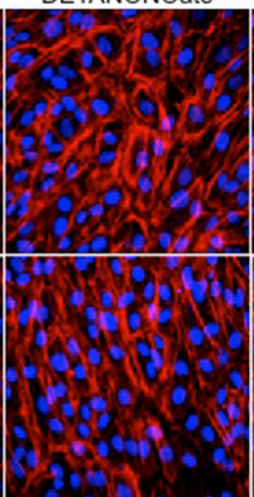

DETANONOate +

$\mathrm{Vi}$

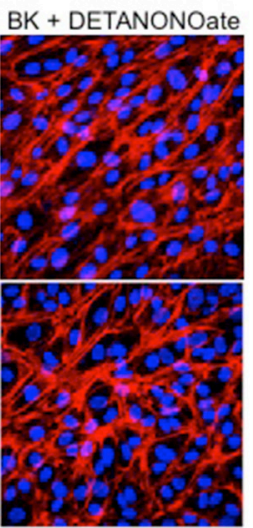

$\mathrm{BK}+$

DETANONOate + Vi
FIGURE 3 | The inhibitory effect of vasoinhibins on BK-induced reduction of transendothelial resistance and actin cytoskeleton rearrangement depends on NO. (A) Time course of TER in BUVEC monolayers cultured in complete medium (Ctl) with or without $10 \mu \mathrm{M}$ BK and the NO synthase inhibitor L-NAME $(10 \mathrm{mM})$. Values are mean \pm s.e.m. from 3 independent experiments normalized to the control. ${ }^{*} P<0.05$ vs. Ctl. (B) Rats were treated with L-NAME $(1.8 \mathrm{mM})$ administered in the drinking water for 15 days, then their retinas were intravitreously injected with PBS (Ctl) or BK (1 nM), and evaluated $2 \mathrm{~h}$ later by the Evans blue dye assay. Values are mean \pm s.e.m. normalized to control. $* P<0.05$ from 8 to 16 independent observations.
(C) Quantification of peak TER values (15 min after treatment start) in BUVEC monolayers cultured in complete medium (Ctl) with or without $10 \mu \mathrm{M} \mathrm{BK}$ and $10 \mathrm{nM} \mathrm{Vi}$ in the absence (white bars) or presence (black bars) of the NO donor DETANONOate $(10 \mu \mathrm{M}) .{ }^{*} P<0.05$ from 3 independent experiments. NS, not significant. BUVEC were cultured on inserts with pore sizes of $8.0 \mu \mathrm{m}$. (D) BUVEC were cultured in complete medium (Ctl) with or without $10 \mu \mathrm{M}$ BK and $10 \mathrm{mM}$ L-NAME, and with the NO donor DETANONOate $(10 \mu \mathrm{M})$ in the presence and in the absence of $\mathrm{BK}$ and $\mathrm{Vi}(10 \mathrm{nM})$ for $15 \mathrm{~min}$, and then actin cytoskeleton (F-actin) distribution was determined using rhodamine-phalloidin. Representative fields are shown. Scale bar, $10 \mu \mathrm{m}$. activation, and that vasoinhibins do not change the amount of B2 receptor.

\section{VASOINHIBINS BLOCK THE REDUCTION OF TRANS-ELECTRICAL RESISTANCE (TER) INDUCED BY BK IN MRCEC, MBCEC, AND BUVEC MONOLAYERS}

The inner BRB refers to the layer of capillaries in the inner retina with very low permeability, due to the interactions between vascular endothelial cells and surrounding cells (pericytes and macroglia) (Klaassen et al., 2013). Freshly isolated mouse retinal (Figure 2A) and brain (Figure 2B) capillary endothelial cells showed stable resistance over time. BK induced a transient decrease in TER that was maximal at $15 \mathrm{~min}$ and was fully prevented by vasoinhibins (Figures 2A,B). Vasoinhibins alone had no effect (Figures 2A,B). Monolayers of BUVEC that express B2 receptors (Wohlfart et al., 1997), also showed stable resistance over time (Figure 2C). BK induced a transient decrease in TER that was maximal at $10 \mathrm{~min}$ (Figures 2C,D) and was fully prevented by vasoinhibins (Figure 2C). Vasoinhibins alone had no effect (Figure 2C). The cytoskeleton is composed of actin microfilaments, which are critical for endothelial cell permeability (Dudek and Garcia, 2001). Treatment with BK induced F-actin redistribution and stress fiber formation in BUVEC (Figure 2E). These effects were blocked by vasoinhibins, and vasoinhibins had no effect alone (Figure 2E).

\section{VASOINHIBINS BLOCK THE BK-INDUCED DECREASE IN BUVEC RESISTANCE AND ACTIN CYTOSKELETON REDISTRIBUTION BY ACTING UPSTREAM OF NO PRODUCTION}

We observed that coadministration of the NOS inhibitor LNAME (Rees et al., 1989) eliminated the BK-induced decrease in TER, but L-NAME alone had no effect (Figure 3A). 
A

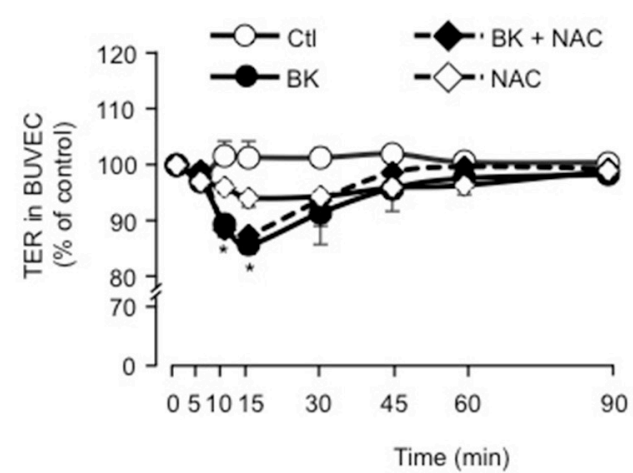

B

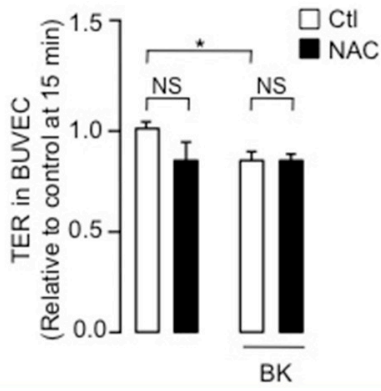

C

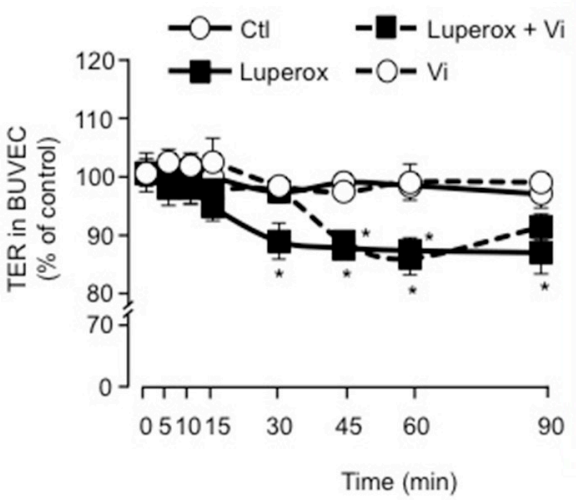

D

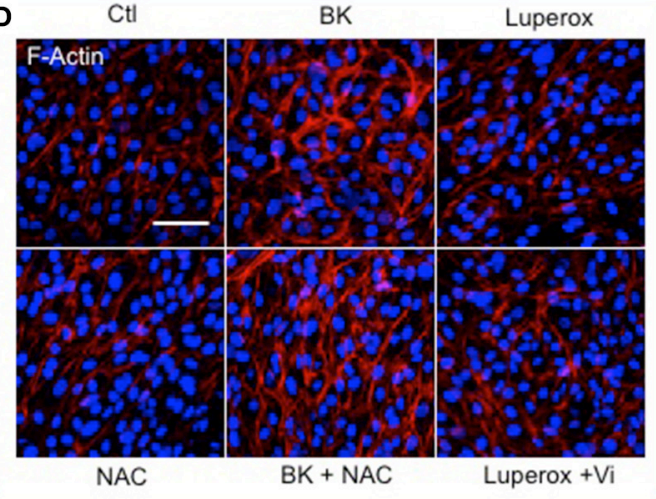

E

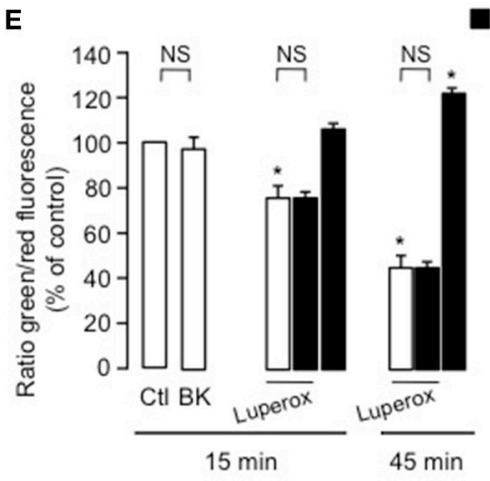

FIGURE 4 | ROS do not participate in the vasoinhibin-mediated inhibition of transendothelial resistance reduction and actin cytoskeleton rearrangement induced by BK. $(\mathbf{A}, \mathbf{C})$ Time course of trans-electrical resistance (TER) in BUVEC monolayers cultured in complete medium (Ct) with or without $10 \mu \mathrm{M}$ BK and the antioxidant $\mathrm{N}$-acetyl cysteine (NAC, $10 \mathrm{mM}$ ) or with or without $500 \mu \mathrm{M}$ Luperox and vasoinhibins $(\mathrm{Vi}, 10 \mathrm{nM})$. BUVEC were cultured on inserts with pore sizes of $8.0 \mu \mathrm{m}$. (B) Corresponding quantification of TER values, $10 \mathrm{~min}$ after treatment initiation. Values correspond to the mean \pm s.e.m. from 3 independent experiments. ${ }^{*} P<0.05$. NS, not significant. (D) BUVEC were cultured in complete medium (Ctl) with or without $10 \mu \mathrm{M}$ BK and
$\mathbf{F}$

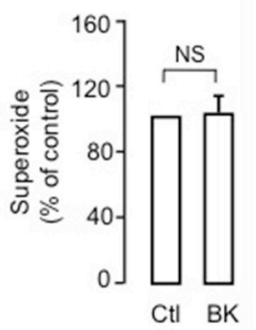

$10 \mathrm{mM}$ NAC or with or without $500 \mu \mathrm{M}$ Luperox and Vi (10 nM) for $15 \mathrm{~min}$, and then actin cytoskeleton (F-actin) distribution was determined using rhodamine-phalloidin. Representative fields are shown. Scale bar, $10 \mu \mathrm{m}$. (E) Mitochondrial membrane potential changes using JC-1 dye in BUVEC monolayers cultured in complete medium (Ctl) with or without $10 \mu \mathrm{M}$ BK or $500 \mu \mathrm{M}$ Luperox and $10 \mathrm{nM}$ Vi. Values correspond to the mean \pm s.e.m. from 3 independent experiments. ${ }^{*} P<0.05$. NS, not significant. (F) Cytosolic levels of superoxide in BUVEC monolayers cultured in complete medium (Ctl) with or without $10 \mu \mathrm{M}$ BK. Values correspond to the mean \pm s.e.m. of 8 repeats per condition from 3 independent experiments.
Administration of L-NAME $(1.8 \mathrm{mM})$ in the rats' drinking water for 15 days also counteracted BK action on BRB permeability (Figure 3B), mimicking the vasoinhibin effect (Figure 1A). In support of NO being essential for BK effects, the NO donor DETANONOate mimicked the BK effect on
TER, and coadministration of DETANONOate did not enhance $\mathrm{BK}$ action (Figure 3C). We then asked whether the NO donor DETANONOate reverts the action of vasoinhibins in the presence of BK. Exogenous NO prevented vasoinhibinmediated inhibition of BK-induced reduction of TER in BUVEC 

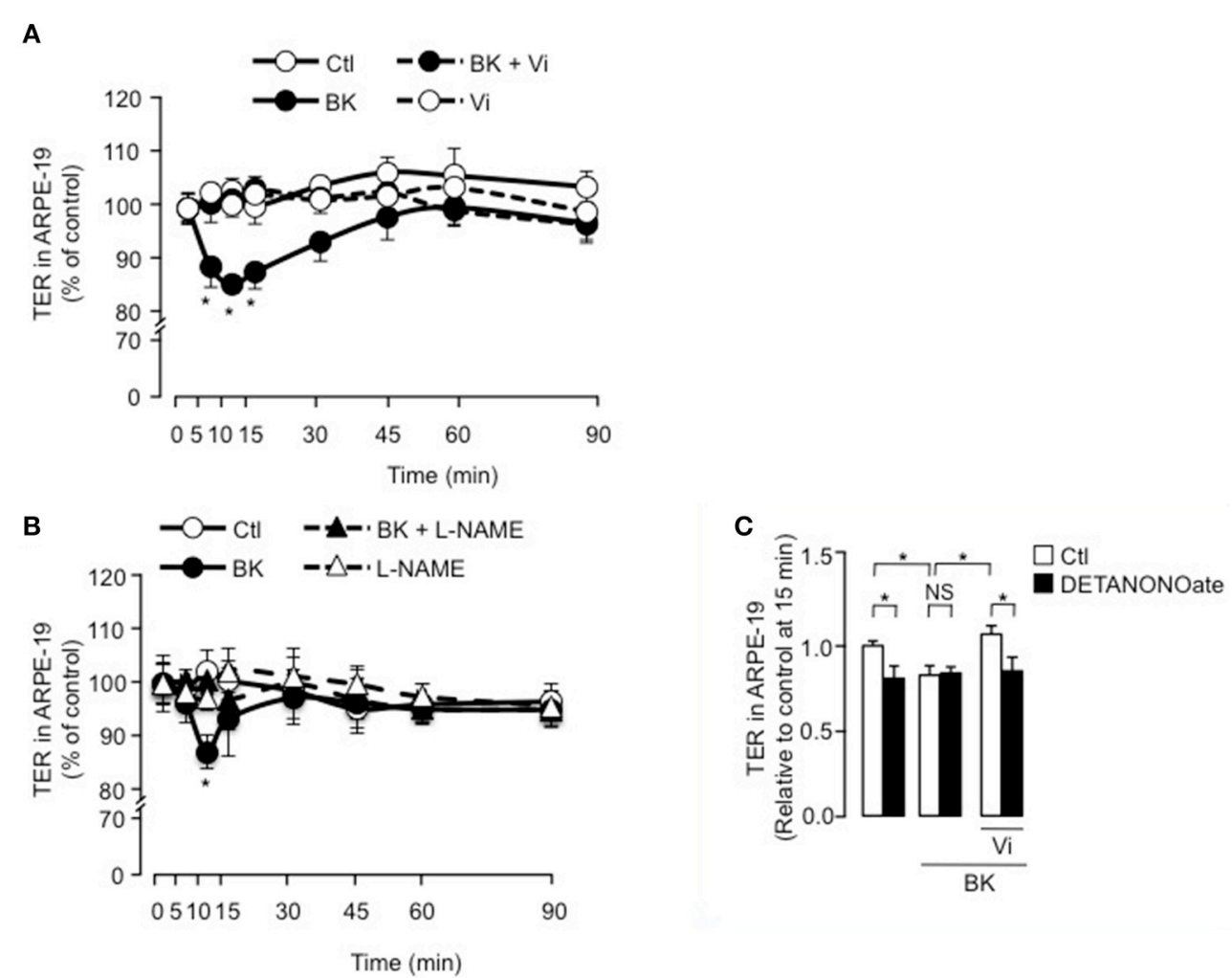

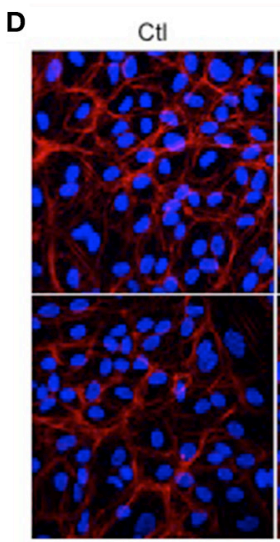

Vi

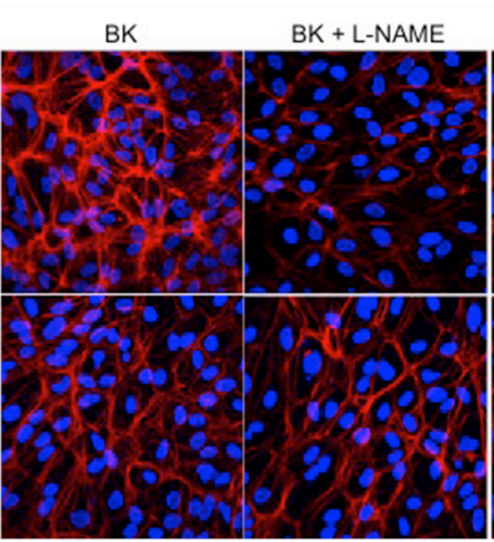

$\mathrm{BK}+\mathrm{Vi}$

L-NAME

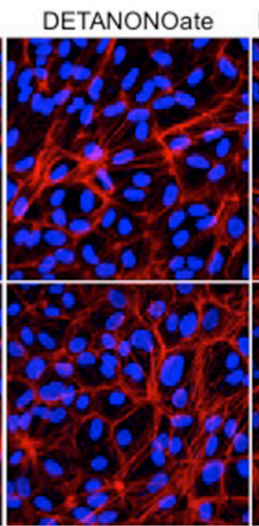

DETANONOate +
BK + DETANONOate

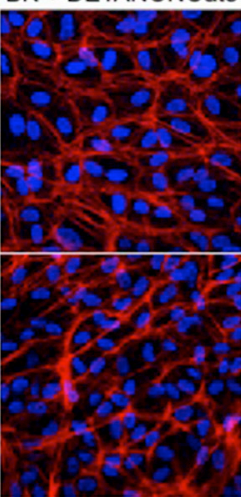

BK + DETANONOate $+\mathrm{Vi}$
FIGURE 5 | BK transiently reduces ARPE-19 cell monolayer resistance and induces actin cytoskeleton rearrangement through NO, and vasoinhibins prevent these effects. $(A, B)$ Time course of trans-electrical resistance (TER) in ARPE-19 monolayers cultured in complete medium (Ctl) with or without $10 \mu \mathrm{M}$ BK and vasoinhibins (Vi, $10 \mathrm{nM})$ or L-NAME $(10 \mathrm{mM})$. Values correspond to the mean \pm s.e.m. from 3 independent experiments. ${ }^{*} P<0.05$ vs. Ctl. (C) Quantification of peak TER values (15 min after treatment start) in ARPE-19 monolayers cultured in complete medium (Ctl) with or without $10 \mu \mathrm{M}$
$\mathrm{BK}$ and $10 \mathrm{nM} \mathrm{Vi}$ in the absence (white bars) or presence (black bars) of the NO donor DETANONOate $(10 \mu \mathrm{M})$. ${ }^{*} P<0.05$ from 3 independent experiments. NS, not significant. ARPE-19 cells were cultured on inserts with pore sizes of $0.4 \mu \mathrm{m}$. (D) ARPE-19 cells were cultured in complete medium (Ctl) with or without $10 \mu \mathrm{M}$ BK and vasoinhibins $(\mathrm{Vi}, 10 \mathrm{nM})$ or L-NAME $(10 \mathrm{mM})$ or the $\mathrm{NO}$ donor DETANONOate $(10 \mu \mathrm{M})$ for $15 \mathrm{~min}$, and then actin cytoskeleton (F-actin) distribution was determined using rhodamine-phalloidin. Representative fields are shown. Scale bar, $10 \mu \mathrm{m}$.
(Figure 3C). In addition, L-NAME prevented BK-induced redistribution of F-actin and stress fiber formation, but had no effect alone (Figure 3D). Also, DETANONOate induced F-actin redistribution and stress fiber formation similarly to $\mathrm{BK}$, and coadministration of DETANONOate did not enhance BK action (Figure 3D). In this context, vasoinhibins were not able to block DETANONOate-induced F-actin rearrangement, and exogenous NO prevented vasoinhibin-mediated inhibition of BK-induced 

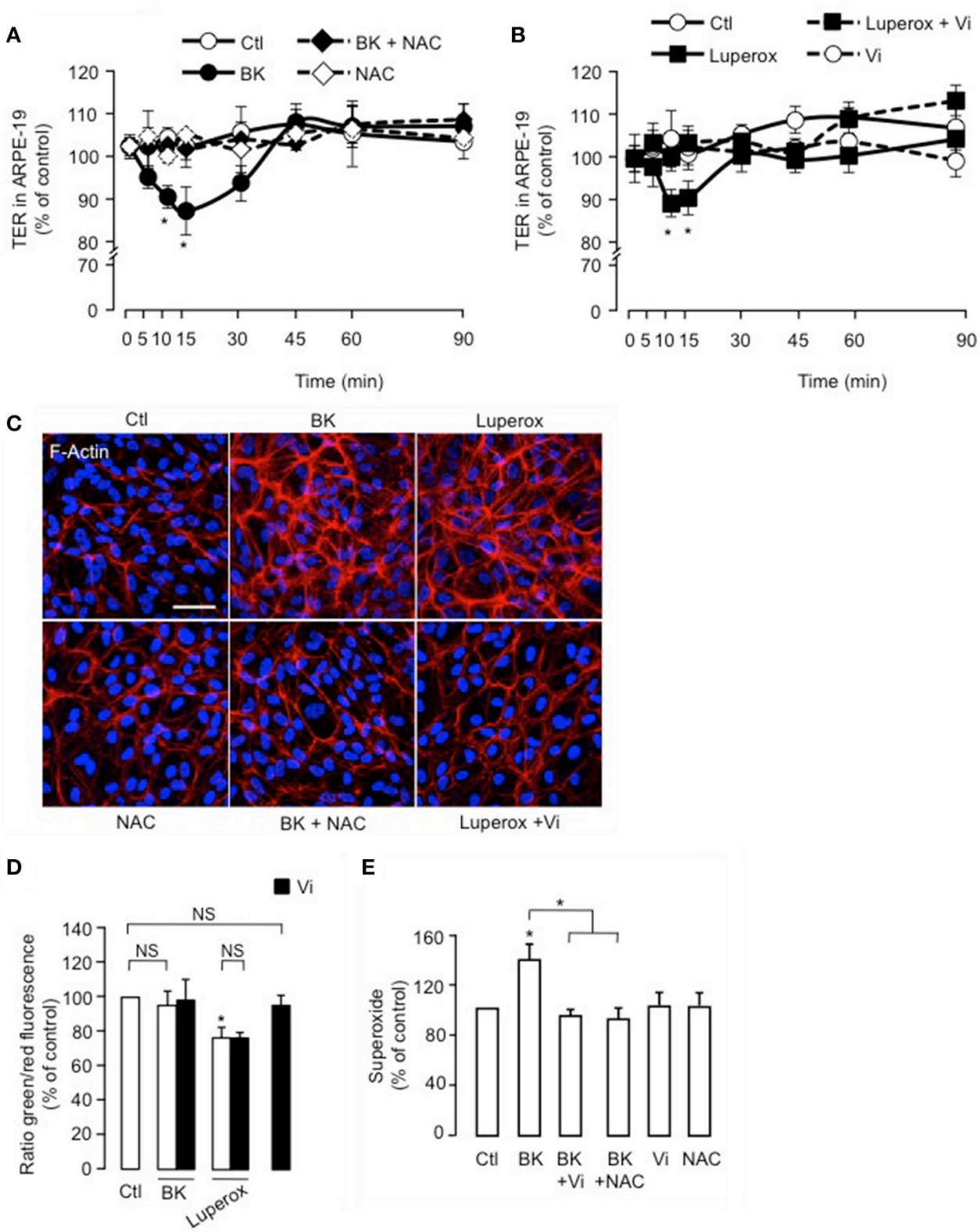

LK Luperox

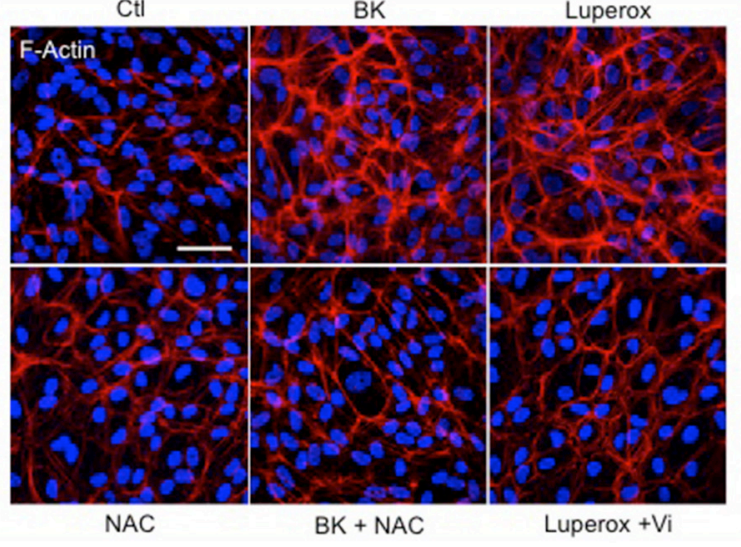

E

FIGURE 6 | ROS contribute to the inhibition of BK-induced decrease of ARPE-19 resistance and actin cytoskeleton rearrangement by vasoinhibins. (A,B) Time course of trans-electrical resistance (TER) in ARPE-19 monolayers cultured in complete medium (Ctl) with or without $10 \mu \mathrm{M}$ BK and N-acetyl cysteine (NAC, $10 \mathrm{mM}$ ) or with or without $500 \mu \mathrm{M}$ Luperox and vasoinhibins $(\mathrm{Vi}, 10 \mathrm{nM})$. Values correspond to the mean \pm s.e.m. from 3 independent experiments. ${ }^{*} P<0.05$ vs. CtI. ARPE-19 cells were cultured on inserts with pore sizes of $0.4 \mu \mathrm{m}$. (C) ARPE-19 cells were cultured in complete medium (Ctl) with or without $10 \mu \mathrm{M} \mathrm{BK}$ and NAC $(10 \mathrm{mM})$ or with or without $500 \mu \mathrm{M}$ Luperox and $\mathrm{Vi}(10 \mathrm{nM})$ for $15 \mathrm{~min}$, and then actin cytoskeleton (F-actin) distribution was determined using rhodamine-phalloidin. Representative fields are shown. Scale bar, $10 \mu \mathrm{m}$. (D) Mitochondrial membrane potential changes using JC-1 dye in ARPE-19 monolayers cultured in complete medium (Ctl) with or without $10 \mu \mathrm{M} \mathrm{BK}$ or $500 \mu \mathrm{M}$ Luperox and Vi (10 nM). Values correspond to the mean \pm s.e.m. from 3 independent experiments. (E) Cytosolic levels of superoxide in ARPE-19 monolayers cultured in complete medium (Ctl) with or without $10 \mu \mathrm{M}$ BK and NAC (10 mM) or with or without $10 \mu \mathrm{M} \mathrm{BK}$ and $\mathrm{Vi}(10 \mathrm{nM})$. Values correspond to the mean \pm s.e.m. of $4-15$ repeats per condition from 3 independent experiments. ${ }^{*} P<0.05$ vs. Ctl. NS, not significant.
F-actin redistribution in BUVEC (Figure 3D). All together, these data show that NO mediates the BK-induced increase in endothelial cell monolayer permeability and actin cytoskeleton redistribution, and that vasoinhibins block these actions by acting upstream of NO production, as previously reported (Gonzalez et al., 2004; Thebault, 2011).

\section{THE VASOINHIBIN-MEDIATED INHIBITION OF TER REDUCTION AND ACTIN CYTOSKELETON REDISTRIBUTION INDUCED BY BK IS INDEPENDENT OF INTRACELLULAR ROS PRODUCTION}

Evidence suggests that increased retinal vascular permeability in response to agonists such as BK is associated with increased ROS load (Wohlfart et al., 1997; Fong et al., 2010), which 
can be reduced inside the cell by free radical scavengers like NAC (Zavodnik et al., 2013). We observed that NAC did not block BK-induced reduction of TER in BUVEC (Figure 4A). Figure $4 \mathrm{~B}$ shows the quantification of TER values at $15 \mathrm{~min}$, when the BK effect was maximal. On the other hand, the free radical initiator Luperox (Zavodnik et al., 2013) did reduce TER in BUVEC after $30 \mathrm{~min}$, an effect that persisted throughout the 90-min recording period (Figure 4C). Vasoinhibins delayed the action of Luperox by $15 \mathrm{~min}$, without affecting the magnitude of its effect (Figure 4C). Furthermore, the BK-induced $\mathrm{F}$-actin redistribution and stress fiber formation was not prevented by the antioxidant NAC, and NAC alone had no effect (Figure 4D). Luperox did not significantly affect F-actin distribution, nor did it when co-administered with vasoinhibins (Figure 4D). Further, we assessed the levels of ROS generated by mitochondrial oxidative phosphorylation, using the JC-1 probe. Levels of ROS were assessed in BUVEC monolayers treated with BK for $15 \mathrm{~min}$, when its decrease of TER is maximal. BK did not modify intracellular ROS levels compared with untreated BUVEC monolayers (Figure 4E). A 15- and 45-min exposure of BUVEC to Luperox decreased the 530/590 optical density ratio, indicating increased levels of intracellular ROS (Figure 4E). Concomittant administration of vasoinhibins did not prevent the Luperox-induced production of ROS. While ROS levels were not modified after a 15-min incubation with vasoinhibins alone, they were reduced when the incubation with vasoinhibins was extended to $45 \mathrm{~min}$ (Figure $4 \mathrm{E}$ ). In addition, ROS can be generated from oxidoreductase enzymes and metal-catalyzed oxidation. However, BK did not modify cytosolic levels of superoxide in BUVEC (Figure 4F). The observations that BK and Luperox acted with different kinetics, that NAC did not block the BK effect, and that BK does not modify the levels of ROS generated as byproducts during mitochondrial electron transport or as intermediates of metal-catalyzed oxidation reactions, indicate that ROS do not contribute to BK action. Our data also show that vasoinhibins delay the ROS effect on transendothelial resistance and that the vasoinhibins per se reduce the intraendothelial levels of ROS.

\section{BK INDUCES A TRANSIENT REDUCTION OF ARPE-19 CELL MONOLAYER RESISTANCE AND AN ACTIN CYTOSKELETON REDISTRIBUTION THAT INVOLVE NO, AND VASOINHIBINS PREVENT THESE EFFECTS}

We then tested if vasoinhibins also target the RPE component of BRB using the ARPE-19 cell line that expresses the B2 receptor (Yasuyoshi et al., 2000; Lim et al., 2008). In control conditions, the ARPE-19 monolayers showed stable resistance over time (Figure 5A). BK induced a transient decrease in TER of ARPE-19 monolayers; this reduction was similar in magnitude (15 \pm 1 vs. $9 \pm 2 \%$ ) and time-course (maximum at $10-15 \mathrm{~min}$ ) to the one observed in BUVEC monolayers. Vasoinhibins prevented the BK-induced decrease in ARPE-19 monolayer resistance, but they had no effect alone (Figure 5A). Similarly, blocking NO production with L-NAME abrogated the action of BK (Figure 5B). Addition of exogenous NO (DETANONOate) reduced TER in ARPE-19 monolayers, mimicking the BK effect, and it prevented vasoinhibins from blocking the BK-induced reduction of TER (Figure 5C). Concomittantly, treatment with BK induced F-actin redistribution in ARPE-19, an effect that was blocked by vasoinhibins (Figure 5D), which had no effect alone (Figure 5D). L-NAME prevented BK-induced F-actin redistribution and had no effect alone (Figure 5D). The NO donor DETANONOate also promoted F-actin redistribution; co-administration of $\mathrm{BK}$ and DETANONOate did not further promote F-actin rearrangement but in the presence of $\mathrm{BK}$ and DETANONOate, vasoinhibins did not inhibit the $\mathrm{F}$-actin redistribution (Figure 5D).

\section{INTRACELLULAR ROS CONTRIBUTE TO THE INHIBITION OF BK-INDUCED DECREASE OF ARPE-19 RESISTANCE AND ACTIN CYTOSKELETON REDISTRIBUTION BY VASOINHIBINS}

The antioxidant NAC blocked BK-induced reduction of TER in ARPE-19 (Figure 6A), but alone, NAC had no effect. Also, Luperox induced a transient decrease in TER that was prevented by vasoinhibins (Figure 6B). Both the magnitude (15 \pm 1 vs. $9 \pm 2 \%$ ) and kinetics (maximum at 10 vs. $15 \mathrm{~min}$ ) of the Luperox effect were similar to those of BK. NAC had no effect alone but blocked the BK-induced F-actin redistribution (Figure 6C). Similarly to BK, Luperox induced F-actin redistribution, an effect that was inhibited by vasoinhibins (Figure 6C). Intracellular levels of ROS were assessed in the presence and absence of vasoinhibins with BK or Luperox for $15 \mathrm{~min}$, when their effects on TER were maximal. BK did not modify ROS levels in ARPE-19, while Luperox increased them (Figure 6D). Alone or combined with BK or Luperox, vasoinhibins had no effect (Figure 6D). In contrast, BK increased cytosolic levels of superoxide in ARPE-19 at $15 \mathrm{~min}$, and both NAC and vasoinhibins blocked this increase (Figure 6E).

\section{VASOINHIBINS REDUCE THE LEVELS OF ROS IN THE RETINA OF STREPTOZOTOCIN-INDUCED DIABETIC RATS}

To assess the physiological relevance of our findings, we analyzed the production of superoxide anion in retinas of rats that were rendered diabetic (Pouliot et al., 2012). Figure 7A shows representative images of retinas stained with the oxidative fluorescent dye DHE (red) and the DNA stain DAPI (blue), and quantification using the mean pixel fluorescence intensity ratio of DHE/DAPI for each nuclear layer of the retina is provided in Figure 7B. In all conditions, the outer segments of photoreceptors were positive for DHE staining due to non-specific autofluorescence (Ling-Ling Zhao et al., 2009). In non-diabetic retinas, the RPE produced more superoxide anion than other layers (shown with an arrow head). After 4 weeks of diabetes, superoxide anion production was enhanced in the RPE (indicated with arrow heads in micrograph), outer nuclear and ganglion cell layers (indicated with asterisks in micrograph), as previously reported (Pouliot et al., 2011). Intravitreal injection of vasoinhibins abolished the diabetes effect on levels of superoxide anions in the RPE and the three nuclear layers of the retina. Alone, vasoinhibins had no effect on basal production of superoxide anions in the retina.

\section{DISCUSSION}

BRB capillary endothelial and RPE cells exhibit regulated transcytotic activity and a tight junctional network that, aided by 


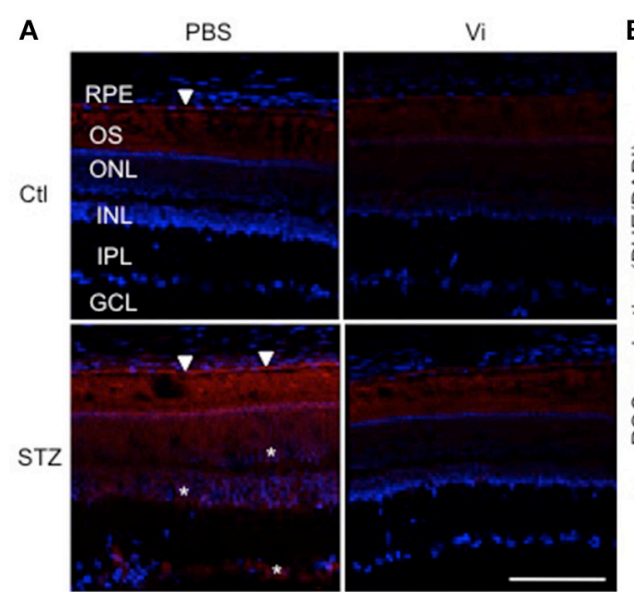

FIGURE 7 | Vasoinhibins reduce the retinal levels of ROS in streptozotocin-induced diabetic rats. (A) Representative images of superoxide anion production stained with dihydroethidium (DHE) on retina sections from control (Ctl) rats intravitreously injected with PBS or vasoinhibins (Vi, $1 \mu \mathrm{M})$ for $24 \mathrm{~h}$ and from streptozotocin (STZ)-induced diabetic rats intravitreously injected with PBS or Vi $24 \mathrm{~h}$ before the end of the

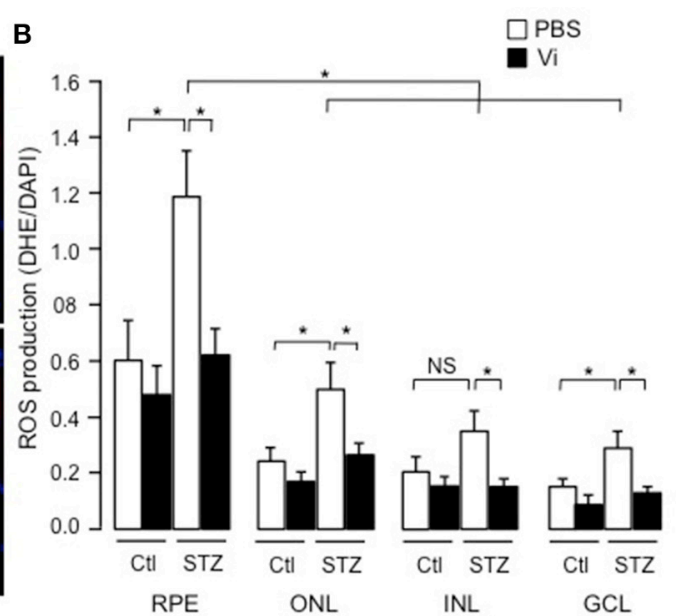

4 weeks of diabetes. Scale bar is $100 \mu \mathrm{m}$. (B) Fluorescence intensity of superoxide anion quantified as mean number of pixels positive for DHE staining normalized to the mean number of pixels positive for DAPI staining in the retinal pigment epithelium (RPE), outer nuclear (ONL), inner nuclear (INL), inner plexiform (IPL), and ganglion cell (GCL) layers. Data are mean \pm s.e.m. of values obtained from 3 rats in each group. ${ }^{*} P<0.05$. NS, not significant. the cytoskeleton, restricts paracellular permeability. Both transand paracellular pathways are the subject of extensive research as they relate to retinal degeneration, edema and inflammation. Notably, increased permeability is a prominent feature of oxidative insult to the retina. Vasoinhibins potently inhibit the increase in retinal vasopermeability associated with diabetes (Garcia et al., 2008), but their effect on the RPE component of the BRB and on oxidant-related mechanisms in the retina is unknown. Here, we show that vasoinhibins regulate BRB permeability by targeting both endothelial and RPE cells, and by limiting excessive oxidative stress in the diabetic retina. BK is an important disruptor of the BRB in diabetes that can be counteracted by vasoinhibins. BK alters not only the vascular but also the RPE compartment. After confirming that NO mediates the BK-induced decrease in endothelial monolayer resistance, we show for the first time that ROS are not involved in this effect but that both NO and ROS are involved in the BK reduction of RPE monolayer resistance. Notably, vasoinhibins prevent BK actions in both endothelial and RPE monolayers.

Consistent with previous studies (Abdouh et al., 2003), we demonstrate that intravitreal injection of $\mathrm{BK}$ in rats stimulates Evans blue dye permeation, indicating increased permeability of the BRB. The dose of BK we used $(10 \mu \mathrm{M})$ promotes vasodilation (Gonzalez et al., 2004), but given that BK binds to the B2 receptor with an $\mathrm{EC}_{50}$ of $2 \mathrm{nM}$ (Gera et al., 2011), we assume that this dose is pharmacological. Nonetheless, high levels of BK may be found in the eye under conditions of diabetic retinopathy, when the levels of carbonic anhydrase I, an enzyme responsible for generating BK (Han et al., 2002; Gao et al., 2007), are $\sim 15$ - and $\sim 8$-times higher than in non-diabetic patients and in patients with diabetes without retinopathy, respectively (Gao et al., 2007). Additionally, vasoinhibins opposed the BK action at concentrations previously demonstrated to prevent the vascular hyperpermeability observed in diabetes (Garcia et al., 2008). Earlier studies found that a B2 receptor antagonist reduces the retinal plasma extravasation induced by BK (Abdouh et al., 2008). Here, we show that Hoe-140, the competitive antagonist of B2 receptors, blocked the $\mathrm{BK}$-induced increase in $\mathrm{BRB}$ transport, as did vasoinhibins. Because $B 1$ receptors were not detected in the retina of rats subjected to $B K$ treatment and because the competitive $\mathrm{B} 2$ receptor antagonist Hoe- 140 fully blocked the BK effect on $\mathrm{BRB}$ permeability, we conclude that the BK-induced increase in BRB transport depends on B2 receptor stimulation. Furthermore, vasoinhibins have been shown to antagonize other B2 receptormediated effects of BK (Gonzalez et al., 2004; Thebault, 2011), the inhibition of phospholipase $\mathrm{C}$ activity being the most upstream target reported for vasoinhibins in the BK signaling pathway (Thebault, 2011). Given that changes in B2 receptor mRNA levels have been detected immediately after stress exposure, leading to changes in protein levels at $3 \mathrm{~h}$ (Nostramo et al., 2013), we postulated that vasoinhibins could down-regulate B2 receptor expression within the 2-h period during which we observed the in vivo effect of BK. However, there were no changes in B2 receptor mRNA and protein levels in the retina of rats subjected to BK treatment with or without vasoinhibins. Consequently, we propose that vasoinhibins negatively regulate $\mathrm{B} 2$ receptor signaling by short-term mechanisms that may include receptor desensitization (Mathis et al., 1996) and internalization (Munoz and Leeb-Lundberg, 1992; Munoz et al., 1993).

Stimulation of B2 receptors has been shown to evoke intracellular $\mathrm{Ca}^{2+}$ mobilization in cultured retinal capillary endothelial cells and to induce vascular permeability, vasodilation, and thickening of the retina, substantiating that the intraocular kallikreinkinin system is functional in the retina (Abdouh et al., 2003). However, the only known BK effects on retinal non-vascular cells are to promote glutamate uptake by ARPE-19 cells (Lim 
et al., 2008) and to decrease retinal glutamate toxicity in cultured retinal neurons (Yasuyoshi et al., 2000). Our data provide the first demonstration that $B K$ transiently reduces the trans-electrical resistance through ARPE-19 cell monolayers. This action shares similarities in amplitude and kinetics with the BK action on endothelial cell monolayers derived from freshly isolated retinal and brain capillary endothelial cells, and also from BUVEC, and it supports the role of BK as a direct regulator of both the inner endothelial and outer RPE components of the $\mathrm{BRB}$. In addition to confirming that $\mathrm{BK}$ enhances transport through the brain-blood barrier (Harford-Wright et al., 2011), these findings extend BK actions to other blood-organ barriers.

Activation of the $\mathrm{B} 2$ receptor stimulates the NO production via Src/PI3kinase/Akt-dependent activation of eNOS (Bae et al., 2003), which has been associated with alterations in endothelial resistance and permeability (Pricci et al., 2003; Wilkinson-Berka, 2004; Frey and Antonetti, 2011). Our findings confirm that exogenous NO reduces the electrical resistance through endothelial monolayers and extend this effect of NO to the RPE. We also found that pharmacological inhibition of NO production leads to inhibition of the BK-induced increase of BRB transport and of permeability through both endothelial and RPE monolayers. Concerning the latter, even though constitutive NOS expression has not been described in ARPE-19 cells, RPE is positive for NADPH-diaphorase, a marker of NOS activity (Goldstein et al., 1996; Fischer and Stell, 1999). Our data also showed that vasoinhibins block the transient decrease in BUVEC and ARPE19 monolayer resistance induced by $\mathrm{BK}$, as did the NO synthase inhibitor L-NAME. In addition, the NO donor DETANONOate prevented vasoinhibins from blocking the BK effect in both cell types, supporting that the vasoinhibin act by inhibiting NO production, as previously demonstrated for endothelial cells (Gonzalez et al., 2004). While this is the first evidence that RPE cells respond to vasoinhibins, we previously demonstrated that vasoinhibins block BK-induced endothelial NO production by inactivating eNOS via two mechanisms: reduced intracellular $\mathrm{Ca}^{2+}$ mobilization (Gonzalez et al., 2004) and activation of protein phosphatase $2 \mathrm{~A}$-induced dephosphorylation at serine $\mathrm{e}^{1179}$ (Garcia et al., 2008; Thebault, 2011).

NO can also stimulate protein kinase $G$, which causes the release of mitochondrial ROS into the cytosol (Oldenburg et al., 2004), and BK induces oxidative stress through an $\mathrm{NO}$-independent mechanism in the human vasculature (Fong et al., 2010). However, neither endothelial nor RPE cells showed increased levels of ROS as byproducts during mitochondrial electron transport in response to BK, which may be due to NOinduced inhibition of ROS production (Kayashima et al., 2012). Indeed, NO produced in response to BK (Gonzalez et al., 2004) may impede ROS production by negatively regulating oxidative phosphorylation through the inhibition of cytochrome $c$ oxidase. Also, BK did not modify the levels of superoxide formed as an intermediate of metal-catalyzed oxidation reactions. Moreover, we found that the radical initiator Luperox induced an increase in endothelial cell permeability with longer latency and duration compared to the effect of $\mathrm{BK}$, and that the antioxidant NAC did not modify the increased permeability due to BK; thus, ROS may not contribute to the BK-induced decrease in endothelial cell resistance.

In contrast, our data indicate that ROS participate in the BKmediated regulation of RPE resistance. Luperox mimicked the BK effect on ARPE-19 monolayer resistance in terms of amplitude, kinetics and actin cytoskeleton rearrangement, coinciding with the disruption of junctional proteins previously reported in association with increased ROS (Miranda et al., 2012; Zavodnik et al., 2013 and present data). BK per se caused superoxide anion, but not ROS, to accumulate in ARPE-19 cells as a by-product during mitochondrial electron transport. Consistent with these data, the antioxidant NAC prevented the decrease in ARPE-19 monolayer resistance induced by BK. Moreover, our data show that vasoinhibins mimicked the effect of NAC and prevented the transient reduction of ARPE-19 resistance induced by Luperox, indicating that vasohibins act by antagonizing ROS. Along this line, the intravitreal injection of vasoinhibins in the diabetic rats reduced the retinal levels of superoxide anion to control values. These data unveil vasoinhibins as potent anti-oxidants in the diabetic retina. We observed that a 45 -min treatment with vasoinhibins diminished ROS levels in endothelial cells. Even though the same in vitro assay showed that vasoinhibins did not block the generation of ROS induced by Luperox, vasoinhibins did inhibit the BK-induced increase of superoxide anion levels in ARPE-19 cells, as did NAC. These findings support the idea that inhibition of ROS production contributes to the vasoinhibin inhibition of permeability. An additional mechanism may be that vasoinhibins promote anti-oxidant mechanisms, thereby protecting RPE against oxidant-mediated monolayer dysfunction (Ho et al., 2006) and endothelial cells from oxidant-mediated permeability dysregulation (Yamagishi et al., 2006; Sheikpranbabu et al., 2010; Kim et al., 2012) and damage (Banumathi et al., 2010; Dou et al., 2012). The pigment epithelium-derived factor (PEDF) acts in this way, and vasoinhibins may, therefore, share some molecular actions with PEDF. Indeed, both vasoinhibins and PEDF stabilize the actin cytoskeleton in both endothelial and RPE cells. Also, vasoinhibins may preserve the reduced/oxidized glutathione ratio (Miura and Roider, 2009) and maintain normal membrane occludin and $\mathrm{N}$-cadherin structure by blocking the ROS-induced stress kinase p38/27-kDa heat shock protein signaling, which is known to mediate actin rearrangement (Ho et al., 2006). Interestingly, prolactin, the molecule from which vasoinhibins originate (Clapp et al., 2006), was recently shown to prevent the decrease in brain-blood barrier permeability induced by metamphetamine by maintaining the levels of claudin-5 and occludin (Rosas-Hernandez et al., 2013).

In conclusion, vasoinhibins prevent the actions of BK on transport through $\mathrm{BRB}$ and on the resistance of endothelium and RPE. Vasoinhibin action is NO-dependent in both endothelial and RPE cells and is ROS-dependent only in the RPE. Consistent with these actions, vasoinhibins reduced the levels of ROS in retinas of streptozotocin-diabetic rats, including the RPE. These data extend the functions of BK in the retina, consolidate our previous findings showing that vasoinhibins protect the BRB under diabetic conditions, and provide novel molecular and cellular insights into the mechanisms of vasoinhibin action in the retina. Ultimately, because preclinical studies have shown that the 
administration of several inhibitors of kinin receptors (Phipps et al., 2009; Clermont et al., 2011; Liu and Feener, 2013) and of vasoinhibins (Ramirez et al., 2011) to diabetic rats ameliorates retinal vascular hyperpermeability and inflammation, this study supports the use of vasoinhibins as therapeutic agents to minimize BRB dysfunction.

\section{AUTHOR CONTRIBUTIONS}

Conceived and designed the experiments: David Arredondo Zamarripa, Carmen Clapp, and Stéphanie Thebault. Performed the experiments: David Arredondo Zamarripa, Nundehui DíazLezama, Rodrigo Meléndez García, Jesús Chávez Balderas, Norma Adán, Maria G. Ledesma-Colunga, Edith Arnold, and Stéphanie Thebault. Analyzed the data: David Arredondo Zamarripa, Nundehui Díaz-Lezama, Rodrigo Meléndez García, and Stéphanie Thebault. Contributed reagents/materials/analysis tools: David Arredondo Zamarripa, Edith Arnold, Maria G. Ledesma-Colunga, Norma Adán, Carmen Clapp, and Stéphanie Thebault. Wrote the paper: David Arredondo Zamarripa, Carmen Clapp, and Stéphanie Thebault.

\section{ACKNOWLEDGMENTS}

This study was supported by the Universidad Nacional Autónoma de México UNAM and the National Council of Science and Technology of Mexico grant CONACYT 176393 and UNAMPAPIIT IN201814. David Arredondo Zamarripa from the "Programa de Doctorado en Ciencias Biomédicas, UNAM" was supported by CONACYT fellowship 269268. We thank F. LópezBarrera, G. Nava, D. Mondragón, A. Prado, A. Castilla, M. García, and E. N. Hernández Ríos for their technical assistance, and D. D. Pless for critically editing the manuscript.

\section{REFERENCES}

Abdouh, M., Khanjari, A., Abdelazziz, N., Ongali, B., Couture, R., and Hassessian, H. M. (2003). Early upregulation of kinin B1 receptors in retinal microvessels of the streptozotocin-diabetic rat. Br. J. Pharmacol. 140, 33-40. doi: 10.1038/sj.bjp.0705210

Abdouh, M., Talbot, S., Couture, R., and Hassessian, H. M. (2008). Retinal plasma extravasation in streptozotocin-diabetic rats mediated by kinin $\mathrm{B}(1)$ and $\mathrm{B}(2)$ receptors. Br. J. Pharmacol. 154, 136-143. doi: 10.1038/bjp.2008.48

Adan, N., Guzman-Morales, J., Ledesma-Colunga, M. G., Perales-Canales, S. I., Quintanar-Stephano, A., Lopez-Barrera, F., et al. (2013). Prolactin promotes cartilage survival and attenuates inflammation in inflammatory arthritis. J. Clin. Invest. 123, 3902-3913. doi: 10.1172/JCI69485

Aranda, J., Rivera, J. C., Jeziorski, M. C., Riesgo-Escovar, J., Nava, G., LopezBarrera, F., et al. (2005). Prolactins are natural inhibitors of angiogenesis in the retina. Invest. Ophthalmol. Vis. Sci. 46, 2947-2953. doi: 10.1167/iovs.05-0173

Arnold, E., Thebault, S., Baeza-Cruz, G., Arredondo Zamarripa, D., Adan, N., Quintanar-Stephano, A., et al. (2014). The hormone prolactin is a novel, endogenous trophic factor able to regulate reactive glia and to limit retinal degeneration. J. Neurosci. 34, 1868-1878. doi: 10.1523/JNEUROSCI.245213.2014

Bae, S. W., Kim, H. S., Cha, Y. N., Park, Y. S., Jo, S. A., and Jo, I. (2003). Rapid increase in endothelial nitric oxide production by bradykinin is mediated by protein kinase A signaling pathway. Biochem. Biophys. Res. Commun. 306, 981-987. doi: 10.1016/S0006-291X(03)01086-6

Banumathi, E., Sheikpranbabu, S., Haribalaganesh, R., and Gurunathan, S. (2010). PEDF prevents reactive oxygen species generation and retinal endothelial cell damage at high glucose levels. Exp. Eye Res. 90, 89-96. doi: 10.1016/j.exer.2009.09.014

Cai, H., Liu, D., and Garcia, J. G. (2008). CaM Kinase II-dependent pathophysiological signalling in endothelial cells. Cardiovasc. Res. 77, 30-34. doi: $10.1093 / \mathrm{cvr} / \mathrm{cvm} 010$
Cajero-Juarez, M., Avila, B., Ochoa, A., Garrido-Guerrero, E., Varela-Echavarria, A., Martinez De La Escalera, G., et al. (2002). Immortalization of bovine umbilical vein endothelial cells: a model for the study of vascular endothelium. Eur. J. Cell Biol. 81, 1-8. doi: 10.1078/0171-9335-00213

Charest-Morin, X., Roy, C., Fortin, E. J., Bouthillier, J., and Marceau, F. (2014). Pharmacological evidence of bradykinin regeneration from extended sequences that behave as peptidase-activated B2 receptor agonists. Front. Pharmacol. 5:32. doi: 10.3389/fphar.2014.00032

Clapp, C., Aranda, J., Gonzalez, C., Jeziorski, M. C., and Martinez De La Escalera, G. (2006). Vasoinhibins: endogenous regulators of angiogenesis and vascular function. Trends Endocrinol. Metab. 17, 301-307. doi: 10.1016/j.tem.2006.08.002

Clapp, C., Martial, J. A., Guzman, R. C., Rentier-Delure, F., and Weiner, R. I. (1993). The 16-kilodalton N-terminal fragment of human prolactin is a potent inhibitor of angiogenesis. Endocrinology 133, 1292-1299.

Clermont, A., Chilcote, T. J., Kita, T., Liu, J., Riva, P., Sinha, S., et al. (2011). Plasma kallikrein mediates retinal vascular dysfunction and induces retinal thickening in diabetic rats. Diabetes 60, 1590-1598. doi: 10.2337/db10-1260

Cossarizza, A., Baccarani-Contri, M., Kalashnikova, G., and Franceschi, C. (1993) A new method for the cytofluorimetric analysis of mitochondrial membrane potential using the J-aggregate forming lipophilic cation $5,5^{\prime}, 6,6^{\prime}$-tetrachloro$1,1^{\prime}, 3,3^{\prime}$-tetraethylbenzimidazolcarbocyanine iodide (JC-1). Biochem. Biophys. Res. Commun. 197, 40-45. doi: 10.1006/bbrc.1993.2438

De Bock, M., Wang, N., Decrock, E., Bol, M., Gadicherla, A. K., Culot, M., et al. (2013). Endothelial calcium dynamics, connexin channels and blood-brain barrier function. Prog. Neurobiol. 108, 1-20. doi: 10.1016/j.pneurobio.2013. 06.001

Doctrow, S. R., Abelleira, S. M., Curry, L. A., Heller-Harrison, R., Kozarich, J. W., Malfroy, B., et al. (1994). The bradykinin analog RMP-7 increases intracellular free calcium levels in rat brain microvascular endothelial cells. J. Pharmacol. Exp. Ther. 271, 229-237.

Dou, G., Sreekumar, P. G., Spee, C., He, S., Ryan, S. J., Kannan, R., et al. (2012). Deficiency of alphaB crystallin augments ER stress-induced apoptosis by enhancing mitochondrial dysfunction. Free Radic. Biol. Med. 53, 1111-1122. doi: 10.1016/j.freeradbiomed.2012.06.042

Dudek, S. M., and Garcia, J. G. (2001). Cytoskeletal regulation of pulmonary vascular permeability. J. Appl. Physiol. (1985) 91, 1487-1500.

Dunn, K., Aotaki-Keen, A. E., Putkey, F. R., and Hjelmeland, L. M. (1996). ARPE19 , a human retinal pigment epithelial cell line with differentiated properties. Exp. Eye Res. 62, 155-169. doi: 10.1006/exer.1996.0020

Easton, A. S., and Abbott, N. J. (2002). Bradykinin increases permeability by calcium and 5-lipoxygenase in the ECV304/C6 cell culture model of the blood-brain barrier. Brain Res. 953, 157-169. doi: 10.1016/S0006-8993(02) 03281-X

Fischer, A. J., and Stell, W. K. (1999). Nitric oxide synthase-containing cells in the retina, pigmented epithelium, choroid, and sclera of the chick eye. J. Comp. Neurol. 405, 1-14.

Fischer, S., Wiesnet, M., Renz, D., and Schaper, W. (2005). H2O2 induces paracellular permeability of porcine brain-derived microvascular endothelial cells by activation of the p44/42 MAP kinase pathway. Eur. J. Cell Biol. 84, 687-697. doi: 10.1016/j.ejcb.2005.03.002

Fong, P., Stafforini, D. M., Brown, N. J., and Pretorius, M. (2010). Increased blood flow induces oxidative stress through an endothelium- and nitric oxide-independent mechanism. Free Radic. Biol. Med. 49, 301-305. doi: 10.1016/j.freeradbiomed.2010.04.023

Frey, T., and Antonetti, D. A. (2011). Alterations to the blood-retinal barrier in diabetes: cytokines and reactive oxygen species. Antioxid. Redox Signal. 15, 1271-1284. doi: 10.1089/ars.2011.3906

Galfione, M., Luo, W., Kim, J., Hawke, D., Kobayashi, R., Clapp, C., et al. (2003). Expression and purification of the angiogenesis inhibitor $16-\mathrm{kDa}$ prolactin fragment from insect cells. Protein Expr. Purif. 28, 252-258. doi: 10.1016/S10465928(02)00639-3

Gao, B. B., Clermont, A., Rook, S., Fonda, S. J., Srinivasan, V. J., Wojtkowski, M., et al. (2007). Extracellular carbonic anhydrase mediates hemorrhagic retinal and cerebral vascular permeability through prekallikrein activation. Nat. Med. 13, 181-188. doi: 10.1038/nm1534

Garcia, C., Aranda, J., Arnold, E., Thebault, S., Macotela, Y., Lopez-Casillas, F., et al. (2008). Vasoinhibins prevent retinal vasopermeability associated with diabetic retinopathy in rats via protein phosphatase $2 \mathrm{~A}$-dependent eNOS inactivation. J. Clin. Invest. 118, 2291-2300. doi: 10.1172/JCI34508 
Gardner, T. W., Antonetti, D. A., Barber, A. J., Lanoue, K. F., and Levison, S. W. (2002). Diabetic retinopathy: more than meets the eye. Surv. Ophthalmol. 47(Suppl. 2), S253-S262. doi: 10.1016/S0039-6257(02)00387-9

Gera, L., Bawolak, M. T., Roy, C., Lodge, R., and Marceau, F. (2011). Design of fluorescent bradykinin analogs: application to imaging of B2 receptormediated agonist endocytosis and trafficking and angiotensin-converting enzyme. J. Pharmacol. Exp. Ther. 337, 33-41. doi: 10.1124/jpet.110.177147

Goldstein, I. M., Ostwald, P., and Roth, S. (1996). Nitric oxide: a review of its role in retinal function and disease. Vision Res. 36, 2979-2994. doi: 10.1016/00426989(96)00017-X

Gonzalez, C., Corbacho, A. M., Eiserich, J. P., Garcia, C., Lopez-Barrera, F., Morales-Tlalpan, V., et al. (2004). 16K-prolactin inhibits activation of endothelial nitric oxide synthase, intracellular calcium mobilization, and endothelium-dependent vasorelaxation. Endocrinology 145, 5714-5722. doi: 10.1210/en.2004-0647

Guo, L., Salt, T. E., Luong, V., Wood, N., Cheung, W., Maass, A., et al. (2007). Targeting amyloid-beta in glaucoma treatment. Proc. Natl. Acad. Sci. U.S.A. 104, 13444-13449. doi: 10.1073/pnas.0703707104

Han, E. D., Macfarlane, R. C., Mulligan, A. N., Scafidi, J., and Davis, A. E. 3rd. (2002). Increased vascular permeability in C1 inhibitor-deficient mice mediated by the bradykinin type 2 receptor. J. Clin. Invest. 109, 1057-1063. doi: 10.1172/JCI200214211

Harford-Wright, E., Lewis, K. M., and Vink, R. (2011). Towards drug discovery for brain tumours: interaction of kinins and tumours at the blood brain barrier interface. Recent Pat. CNS Drug Discov. 6, 31-40. doi: 10.2174/157488911794079118

Ho, T. C., Yang, Y. C., Cheng, H. C., Wu, A. C., Chen, S. L., and Tsao, Y. P. (2006). Pigment epithelium-derived factor protects retinal pigment epithelium from oxidant-mediated barrier dysfunction. Biochem. Biophys. Res. Commun. 342, 372-378. doi: 10.1016/j.bbrc.2006.01.164

Kayashima, Y., Smithies, O., and Kakoki, M. (2012). The kallikrein-kinin system and oxidative stress. Curr. Opin. Nephrol. Hypertens. 21, 92-96. doi: 10.1097/MNH.0b013e32834d54b1

Kim, J. H., Lee, S. J., Kim, K. W., and Yu, Y. S. (2012). Oxidized low density lipoprotein-induced senescence of retinal pigment epithelial cells is followed by outer blood-retinal barrier dysfunction. Int. J. Biochem. Cell Biol. 44, 808-814. doi: 10.1016/j.biocel.2012.02.005

Klaassen, I., Van Noorden, C. J., and Schlingemann, R. O. (2013). Molecular basis of the inner blood-retinal barrier and its breakdown in diabetic macular edema and other pathological conditions. Prog. Retin. Eye Res. 34, 19-48. doi: 10.1016/j.preteyeres.2013.02.001

Leeb-Lundberg, L. M., Marceau, F., Muller-Esterl, W., Pettibone, D. J., and Zuraw, B. L. (2005). International union of pharmacology. XLV. Classification of the kinin receptor family: from molecular mechanisms to pathophysiological consequences. Pharmacol. Rev. 57, 27-77. doi: 10.1124/pr.57.1.2

Lim, S. K., Han, H. J., Kim, K. Y., and Park, S. H. (2009). Both B1R and $\mathrm{B} 2 \mathrm{R}$ act as intermediate signaling molecules in high glucose-induced stimulation of glutamate uptake in ARPE cells. J. Cell. Physiol. 221, 677-687. doi: 10.1002/jcp. 21906

Lim, S. K., Park, M. J., Jung, H. K., Park, A. Y., Kim, D. I., Kim, J. C., et al. (2008). Bradykinin stimulates glutamate uptake via both B1R and B2R activation in a human retinal pigment epithelial cells. Life Sci. 83, 761-770. doi: 10.1016/j.lfs.2008.09.014

Ling-Ling Zhao, J.-L. Q., Dan-Ni, C., and Han-Ben, N. (2009). Layered-resolved autofluorescence imaging of photoreceptors using two-photon excitation. J. Biomed. Sci. Eng. 2, 3. doi: 10.4236/jbise.2009.25052

Liu, J., and Feener, E. P. (2013). Plasma kallikrein-kinin system and diabetic retinopathy. Biol. Chem. 394, 319-328. doi: 10.1515/hsz-2012-0316

Ma, J. X., Song, Q., Hatcher, H. C., Crouch, R. K., Chao, L., and Chao, J. (1996). Expression and cellular localization of the kallikrein-kinin system in human ocular tissues. Exp. Eye Res. 63, 19-26. doi: 10.1006/exer.1996.0087

Marceau, F., and Regoli, D. (2004). Bradykinin receptor ligands: therapeutic perspectives. Nat. Rev. Drug Discov. 3, 845-852. doi: 10.1038/nrd1522

Mathis, S. A., Criscimagna, N. L., and Leeb-Lundberg, L. M. (1996). B1 and $\mathrm{B} 2$ kinin receptors mediate distinct patterns of intracellular $\mathrm{Ca} 2+$ signaling in single cultured vascular smooth muscle cells. Mol. Pharmacol. 50, $128-139$.

Miranda, S., Gonzalez-Rodriguez, A., Garcia-Ramirez, M., Revuelta-Cervantes, J., Hernandez, C., Simo, R., et al. (2012). Beneficial effects of fenofibrate in retinal pigment epithelium by the modulation of stress and survival signaling under diabetic conditions. J. Cell. Physiol. 227, 2352-2362. doi: 10.1002/jcp.22970

Miura, Y., and Roider, J. (2009). Triamcinolone acetonide prevents oxidative stressinduced tight junction disruption of retinal pigment epithelial cells. Graefes Arch. Clin. Exp. Ophthalmol. 247, 641-649. doi: 10.1007/s00417-009-1041-6

Munoz, C. M., Cotecchia, S., and Leeb-Lundberg, L. M. (1993). B2 kinin receptormediated internalization of bradykinin in DDT1 MF-2 smooth muscle cells is paralleled by sequestration of the occupied receptors. Arch. Biochem. Biophys. 301, 336-344. doi: 10.1006/abbi.1993.1153

Munoz, C. M., and Leeb-Lundberg, L. M. (1992). Receptor-mediated internalization of bradykinin. DDT1 MF-2 smooth muscle cells process internalized bradykinin via multiple degradative pathways. J. Biol. Chem. 267, 303-309.

Nostramo, R., Tillinger, A., Serova, L., Kvetnansky, R., and Sabban, E. L. (2013). Bradykinin B2 receptor in the adrenal medulla of male rats and mice: glucocorticoid-dependent increase with immobilization stress. Endocrinology 154, 3729-3738. doi: 10.1210/en.2013-1406

Oldenburg, O., Qin, Q., Krieg, T., Yang, X. M., Philipp, S., Critz, S. D., et al. (2004). Bradykinin induces mitochondrial ROS generation via NO, cGMP, PKG, and mitoKATP channel opening and leads to cardioprotection. Am. J. Physiol. Heart Circ. Physiol. 286, H468-H476. doi: 10.1152/ajpheart.00360.2003

Phagoo, S. B., Poole, S., and Leeb-Lundberg, L. M. (1999). Autoregulation of bradykinin receptors: agonists in the presence of interleukin-1beta shift the repertoire of receptor subtypes from B2 to B1 in human lung fibroblasts. Mol. Pharmacol. 56, 325-333.

Phipps, J. A., Clermont, A. C., Sinha, S., Chilcote, T. J., Bursell, S. E., and Feener, E. P. (2009). Plasma kallikrein mediates angiotensin II type 1 receptor-stimulated retinal vascular permeability. Hypertension 53, 175-181. doi: 10.1161/HYPERTENSIONAHA.108.117663

Pouliot, M., Hetu, S., Lahjouji, K., Couture, R., and Vaucher, E. (2011). Modulation of retinal blood flow by kinin B(1) receptor in Streptozotocin-diabetic rats. Exp. Eye Res. 92, 482-489. doi: 10.1016/j.exer.2011.03.007

Pouliot, M., Talbot, S., Senecal, J., Dotigny, F., Vaucher, E., and Couture, R. (2012). Ocular application of the kinin B1 receptor antagonist LF22-0542 inhibits retinal inflammation and oxidative stress in streptozotocin-diabetic rats. PLoS ONE 7:e33864. doi: 10.1371/journal.pone.0033864

Pricci, F., Leto, G., Amadio, L., Iacobini, C., Cordone, S., Catalano, S., et al. (2003). Oxidative stress in diabetes-induced endothelial dysfunction involvement of nitric oxide and protein kinase C. Free Radic. Biol. Med. 35, 683-694. doi: 10.1016/S0891-5849(03)00401-5

Qin, S., and Rodrigues, G. A. (2010). Differential roles of AMPKalphal and AMPKalpha2 in regulating 4-HNE-induced RPE cell death and permeability. Exp. Eye Res. 91, 818-824. doi: 10.1016/j.exer.2010.10.007

Ramirez, M., Wu, Z., Moreno-Carranza, B., Jeziorski, M. C., Arnold, E., DiazLezama, N., et al. (2011). Vasoinhibin gene transfer by adenoassociated virus type 2 protects against VEGF- and diabetes-induced retinal vasopermeability. Invest. Ophthalmol. Vis. Sci. 52, 8944-8950. doi: 10.1167/iovs.11-8190

Raslan, F., Schwarz, T., Meuth, S. G., Austinat, M., Bader, M., Renne, T., et al. (2010). Inhibition of bradykinin receptor B1 protects mice from focal brain injury by reducing blood-brain barrier leakage and inflammation. J. Cereb. Blood Flow Metab. 30, 1477-1486. doi: 10.1038/jcbfm.2010.28

Rees, D. D., Palmer, R. M., Hodson, H. F., and Moncada, S. (1989). A specific inhibitor of nitric oxide formation from L-arginine attenuates endotheliumdependent relaxation. Br. J. Pharmacol. 96, 418-424. doi: 10.1111/j.14765381.1989.tb11833.x

Revest, P. A., Abbott, N. J., and Gillespie, J. I. (1991). Receptor-mediated changes in intracellular $[\mathrm{Ca} 2+]$ in cultured rat brain capillary endothelial cells. Brain Res. 549, 159-161. doi: 10.1016/0006-8993(91)90614-2

Rosas-Hernandez, H., Cuevas, E., Lantz-Mcpeak, S. M., Ali, S. F., and Gonzalez, C. (2013). Prolactin protects against the methamphetamineinduced cerebral vascular toxicity. Curr. Neurovasc. Res. 10, 346-355. doi: $10.2174 / 15672026113109990031$

Sainz, I. M., Pixley, R. A., and Colman, R. W. (2007). Fifty years of research on the plasma kallikrein-kinin system: from protein structure and function to cell biology and in-vivo pathophysiology. Thromb. Haemost. 98, 77-83. doi: 10.1160/TH07-04-0250

Sheikpranbabu, S., Haribalaganesh, R., Lee, K. J., and Gurunathan, S. (2010). Pigment epithelium-derived factor inhibits advanced glycation end products-induced retinal vascular permeability. Biochimie 92, 1040-1051. doi: 10.1016/j.biochi.2010.05.004 
Smith, A. J., Lewis, F. C., Aquila, I., Waring, C. D., Nocera, A., Agosti, V., et al. (2014). Isolation and characterization of resident endogenous c-Kit+ cardiac stem cells from the adult mouse and rat heart. Nat. Protoc. 9, 1662-1681. doi: 10.1038/nprot.2014.113

Takeda, H., Kimura, Y., Higashida, H., and Yokoyama, S. (1999). Localization of B2 bradykinin receptor mRNA in the rat retina and sclerocornea. Immunopharmacology 45, 51-55. doi: 10.1016/S0162-3109(99)00057-0

Teshima, Y., Takahashi, N., Nishio, S., Saito, S., Kondo, H., Fukui, A., et al. (2014). Production of reactive oxygen species in the diabetic heart. Roles of mitochondria and NADPH oxidase. Circ. J. 78, 300-306. doi: 10.1253/circj.CJ-13-1187

Thebault, S. (2011). Vasoinhibins prevent Bradykinin-stimulated endothelial cell proliferation by Inactivating eNOS via reduction of both intracellular $\mathrm{Ca} 2+$ levels and eNOS phosphorylation at Ser1179. Pharmaceuticals (Basel). 4, 1052-1069. doi: 10.3390/ph4071052

Wilkinson-Berka, J. L. (2004). Vasoactive factors and diabetic retinopathy: vascular endothelial growth factor, cycoloxygenase-2 and nitric oxide. Curr. Pharm. Des. 10, 3331-3348. doi: 10.2174/1381612043383142

Wohlfart, P., Dedio, J., Wirth, K., Scholkens, B. A., and Wiemer, G. (1997). Different B1 kinin receptor expression and pharmacology in endothelial cells of different origins and species. J. Pharmacol. Exp. Ther. 280, 1109-1116.

Xu, Q., Qaum, T., and Adamis, A. P. (2001). Sensitive blood-retinal barrier breakdown quantitation using Evans blue. Invest. Ophthalmol. Vis. Sci. 42, 789-794.

Yamagishi, S., Nakamura, K., Matsui, T., Inagaki, Y., Takenaka, K., Jinnouchi, Y., et al. (2006). Pigment epithelium-derived factor inhibits advanced glycation end product-induced retinal vascular hyperpermeability by blocking reactive oxygen species-mediated vascular endothelial growth factor expression. J. Biol. Chem. 281, 20213-20220. doi: 10.1074/jbc.M602110200

Yasuyoshi, H., Kashii, S., Zhang, S., Nishida, A., Yamauchi, T., Honda, Y., et al. (2000). Protective effect of bradykinin against glutamate neurotoxicity in cultured rat retinal neurons. Invest. Ophthalmol. Vis. Sci. 41, 2273-2278.
Zavodnik, I. B., Dremza, I. K., Cheshchevik, V. T., Lapshina, E. A., and Zamaraewa, M. (2013). Oxidative damage of rat liver mitochondria during exposure to tbutyl hydroperoxide. Role of $\mathrm{Ca}(2)(+)$ ions in oxidative processes. Life Sci. 92, 1110-1117. doi: 10.1016/j.lfs.2013.04.009

Zech, J. C., Pouvreau, I., Cotinet, A., Goureau, O., Le Varlet, B., and De Kozak, Y. (1998). Effect of cytokines and nitric oxide on tight junctions in cultured rat retinal pigment epithelium. Invest. Ophthalmol. Vis. Sci. 39, 1600-1608.

Zheng, L., and Kern, T. S. (2009). Role of nitric oxide, superoxide, peroxynitrite and PARP in diabetic retinopathy. Front. Biosci. (Landmark Ed.) 14, 3974-3987. doi: $10.2741 / 3505$

Conflict of Interest Statement: The authors declare that the research was conducted in the absence of any commercial or financial relationships that could be construed as a potential conflict of interest.

Received: 06 June 2014; accepted: 30 September 2014; published online: 20 October 2014.

Citation: Arredondo Zamarripa D, Díaz-Lezama N, Meléndez García R, Chávez Balderas J, Adán N, Ledesma-Colunga MG, Arnold E, Clapp C and Thebault S (2014) Vasoinhibins regulate the inner and outer blood-retinal barrier and limit retinal oxidative stress. Front. Cell. Neurosci. 8:333. doi: 10.3389/fncel.2014.00333

This article was submitted to the journal Frontiers in Cellular Neuroscience.

Copyright (c) 2014 Arredondo Zamarripa, Díaz-Lezama, Meléndez García, Chávez Balderas, Adán, Ledesma-Colunga, Arnold, Clapp and Thebault. This is an openaccess article distributed under the terms of the Creative Commons Attribution License (CC BY). The use, distribution or reproduction in other forums is permitted, provided the original author(s) or licensor are credited and that the original publication in this journal is cited, in accordance with accepted academic practice. No use, distribution or reproduction is permitted which does not comply with these terms. 